\title{
Effective unwrapping of complicated phases by exploiting multiple interferograms: a case study of the 2016 Kumamoto earthquake
}

Yu Morishita* (1)

\begin{abstract}
Synthetic aperture radar (SAR) interferometry can measure ground surface deformation with high accuracy and spatial resolution, in the form of phase change in an interferogram. The phase is observed modulo $2 \pi$ (i.e., wrapped), and unwrapping is necessary to obtain the absolute amount of deformation. Although several advanced automatic unwrapping algorithms and approaches have been proposed, unwrapping errors can occur, especially in complicated phases. Manual adjustment of the integration path in the unwrapping may improve the unwrapping result. However, sometimes, it tends to be challenging even for an expert. In this report, I describe an effective unwrapping approach for complicated phases to obtain a reliable unwrapping result using multiple interferograms. A common integration path guide is created from geocoded interferograms and their phase noise coherence estimates, which reduces/eliminates the effort involved in manual adjustment and greatly reduces unwrapping errors. The remaining unwrapping errors were detected from residuals between the unwrapped phases of multiple interferograms and corrected based on isolated components. A case study was taken up in the northwest of the outer rim of the Aso caldera. Here, plenty of displacement lineaments were generated by the 2016 Kumamoto earthquake, resulting in severely complicated interferometric phases to correctly unwrap by any existing approaches. Therefore, the proposed approach effectively and efficiently retrieves reliable unwrapped phases and subsequent significant interpretations of the displacement lineaments. This effective unwrapping approach may reveal complicated deformations and unrecognized mechanisms in future earthquakes or other deformation-causing geophysical phenomena.
\end{abstract}

Keywords: Synthetic aperture radar, Phase unwrapping, 2016 Kumamoto earthquake, Displacement lineament 


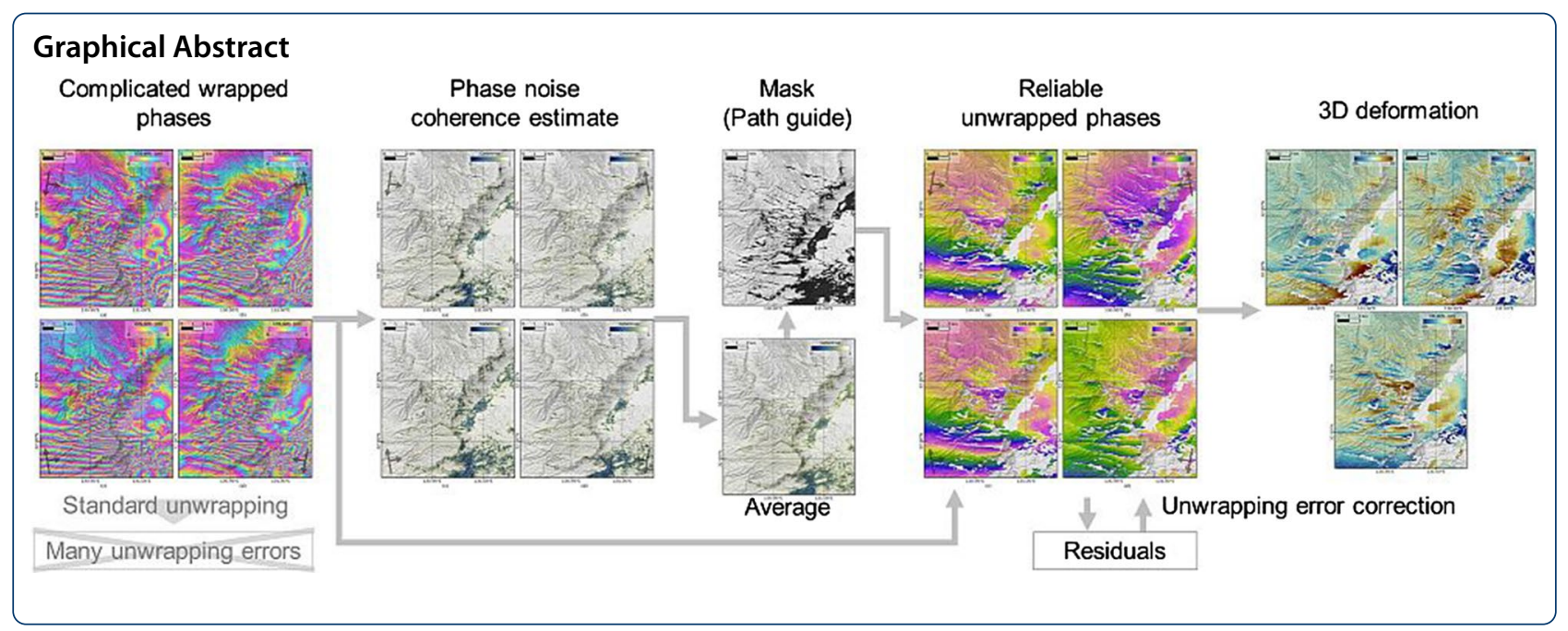

\section{Introduction}

Interferometric Synthetic Aperture Radar (InSAR) is capable of measuring ground surface deformation with significant accuracy and high spatial resolution (e.g., Massonnet et al. 1993; Hanssen 2001). The deformation between two SAR acquisition causes a line-of-sight (LOS) phase change in an interferogram. As the phase change is observed modulo $2 \pi$, the absolute deformation amount can be obtained through phase unwrapping (i.e., retrieval of the integer ambiguity number of cycles). However, incorrect estimates of the integer ambiguity (i.e., unwrapping errors) often occur, because the two-dimensional unwrapping in real data is generally an ill-posed inverse problem (e.g., Zebker and Lu 1998; Yu et al. 2019). In particular, if an interferogram includes significant decorrelation noise or complicated deformation, unwrapping errors tend to occur and prevent us from obtaining the correct deformation.

Fujiwara et al. $(2016,2020)$ detected several displacement lineaments in the northwest of the outer rim of the Aso caldera triggered by the 2016 Kumamoto earthquake with Advanced Land Observing Satellite 2 (ALOS-2) interferograms. The spatial pattern of the phases associated with the lineaments in the interferograms were too complicated to be correctly unwrapped using existing algorithms.

In this technical report, I describe the details of an effective unwrapping approach to obtain reliable unwrapped phases using multiple interferograms based on a case study of the 2016 Kumamoto earthquake.

\section{Basics of phase unwrapping}

Phases in a differential interferogram can be utilized to measure the LOS surface displacements that occurs between acquisitions. As the phases are wrapped (i.e., modulo $2 \pi$ ), phase unwrapping is necessary to retrieve deformation with an amplitude larger than the $\pi$ radian (corresponding to a quarter-wavelength in a unit of length; e.g., $\sim 6 \mathrm{~cm}$ in L-band). The basic concept of unwrapping is to integrate neighboring phases under the assumption that the phase difference between neighboring pixels is less than $\pi$ (e.g., Zebker and $\mathrm{Lu}$ 1998; Yu et al. 2019). If this assumption holds for all pixels, the unwrapping procedure provides a unique solution. However, in real interferograms, the assumption often fails (i.e., the real phase difference is larger than $\pi$ ) because of noise or deformation. The unwrapped results may differ depending on the integration path. To obtain the correct unwrapped result, the integration path must avoid phase discontinuities. Several advanced automatic unwrapping algorithms and approaches have been proposed to obtain a solution as reliable as possible (please refer to Yu et al. (2019) and the references therein for more details). Manual adjustment of the integration path by adding cuts is also useful in case of failure of the automatic procedures; however, this is difficult for a non-expert and tends to be troublesome for complicated phases (Zebker and $\mathrm{Lu}$ 1998). Moreover, several deep learning-based approaches have recently been proposed and have demonstrated promising advancements from existing algorisms (e.g., Zhou et al. 2020, 2021; Sica et al. 2020; Wu et al. 2021), although they are yet to be used widely or easily.

\section{The area of case study and data implemented}

The mainshock of the 2016 Kumamoto earthquake sequence with a Japan Meteorological Agency (JMA) magnitude (Mj) of 7.3 occurred on April 15, 2016 (16:25 UTC) following large foreshocks with Mj 6.5 and 6.4 on 
April 14 (12:26 and 15:03 UTC, respectively). Fujiwara et al. $(2016,2020)$ identified several displacement lineaments triggered by the mainshock, apart from the seismogenic Futagawa and Hinagu faults. In particular, in the northwest of the outer rim of the Aso caldera, several dozens of near-parallel lineaments were generated, some that correspond to known active faults (Fig. 1).

Four ALOS-2 interferograms from different directions were utilized in Fujiwara et al. $(2016,2020)$ and also implemented in the present study (Table 1). Acquisitions with the shortest temporal baseline were selected to obtain as high coherence as possible. Interferometric processing was conducted using the GSISAR software
(Tobita 2003; Morishita 2019). The $10 \mathrm{~m}$ mesh digital elevation model (DEM) prepared by the Geospatial Information Authority of Japan (GSI) was utilized to remove topographic phases. The multilook factors for the ultrafine (84 $\mathrm{MHz}$ range bandwidth) and high sensitive $(42 \mathrm{MHz}$ ) modes were $4 \times 4$ and $2 \times 4$ in range $\times$ azimuth, respectively. This was implemented to reduce noise but maintain the highest spatial resolution possible and uniform the spatial resolution between different observation modes. Tropospheric and ionospheric noise correction using the numerical weather model (Kobayashi 2016) and the split-spectrum method (Gomba et al. 2016; Wegmüller et al. 2018), respectively, were applied. Furthermore, a

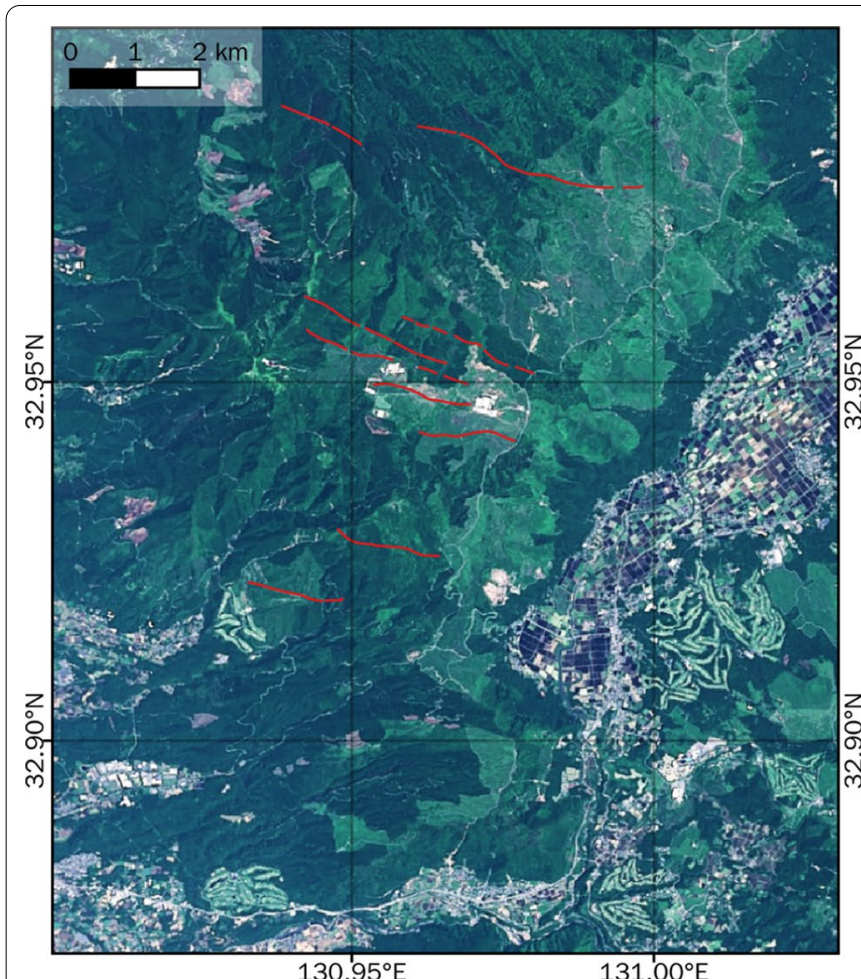

(a)

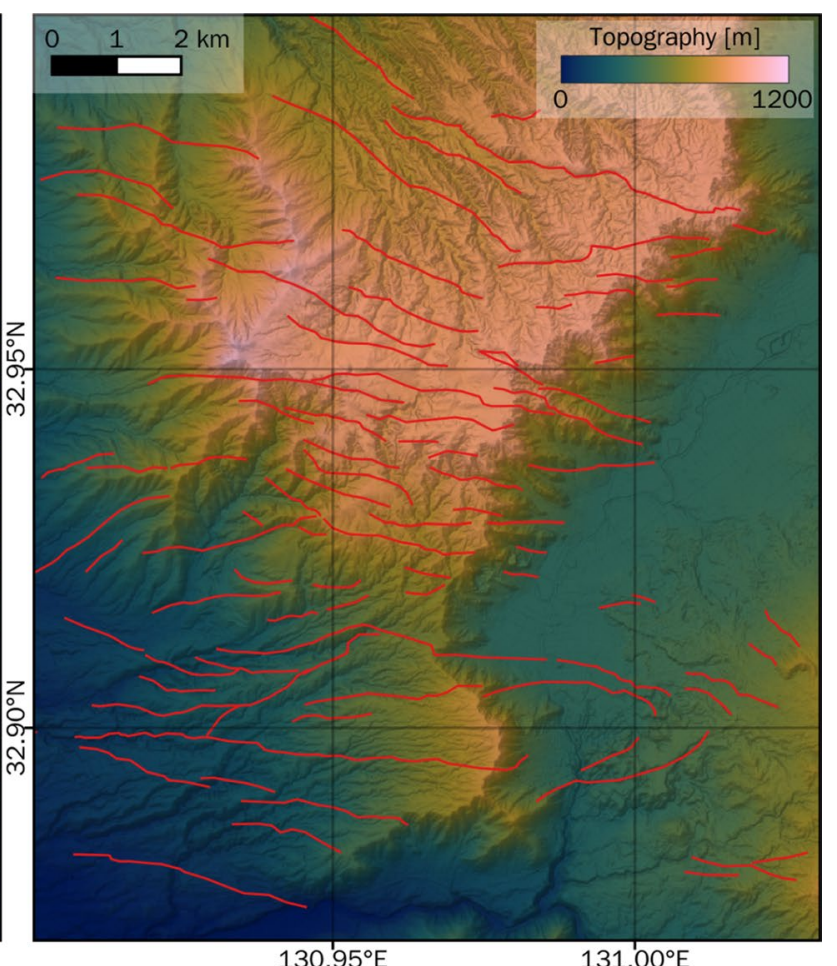

(b)

Fig. 1 a Optical image in the northwest of the outer rim of the Aso caldera. The red lines denote known active faults (Nakata and Imaizumi 2002). b Topography. The red lines denote the displacement lineaments identified by Fujiwara et al. $(2016,2020)$

Table 1 ALOS-2 data utilized in this study

\begin{tabular}{|c|c|c|c|c|c|c|c|c|}
\hline & \multirow[t]{2}{*}{ Path } & \multirow[t]{2}{*}{ Frame } & \multirow[t]{2}{*}{ Ascending/descending } & \multirow[t]{2}{*}{ Right/left } & \multirow[t]{2}{*}{ Mode } & \multirow[t]{2}{*}{ Off-nadir angle } & \multicolumn{2}{|c|}{ Dates [yy/mm/dd] } \\
\hline & & & & & & & Primary & Secondary \\
\hline (a) & 028 & 2920 & Descending & Left & Ultrafine & $29.1^{\circ}$ & $16 / 04 / 15$ & $16 / 04 / 29$ \\
\hline (b) & 126 & 0670 & Ascending & Left & Ultrafine & $21.9^{\circ}$ & $16 / 04 / 15$ & $16 / 04 / 29$ \\
\hline (c) & 130 & 0650 & Ascending & Right & High sensitive & $30.4^{\circ}$ & 15/12/03 & $16 / 04 / 21$ \\
\hline (d) & 023 & 2950 & Descending & Right & Ultrafine & $32.4^{\circ}$ & 16/03/07 & $16 / 04 / 18$ \\
\hline
\end{tabular}


modified Goldstein filter based on coherence (Baran et al. 2003) was applied. Later, the wrapped interferograms in the radar coordinates were geocoded into common geographical grids with a pixel spacing of $\sim 11 \mathrm{~m}$.

The produced wrapped interferograms demonstrate remarkably complicated phases because of the large number of displacement lineaments (Figs. 2 and 3). In this study, the statistical-cost network flow algorithm for phase unwrapping (SNAPHU) with minimum-spanning-tree initialization was implemented to unwrap the interferograms (Chen and Zebker 2000, 2001). The unwrapped phases contained several evident unwrapping errors, indicating that the deformation could not be correctly retrieved (Fig. 4).

\section{Effective common path guide creation from multiple geocoded interferograms}

In this case study, most of the unwrapping errors emerged at pixels, where the phase integration path crossed offsets with $>\pi$ radians, caused by displacement lineaments. A path guide for avoiding offsets is necessary to prevent unwrapping errors. As the distribution of the displacement lineaments is remarkably complicated (Figs. 1, 2, 3), it seems impossible to create a reliable path guide by any existing algorithms and extremely difficult to conduct manual adjustment.

Here, I propose an effective method to create a reliable path guide from multiple geocoded interferograms. In general, unwrapping is executed on interferograms in the radar coordinates before geocoding, mainly because the geocoding procedure loses original phase information by interpolation; hence, the spatial resolution in the radar coordinates is slightly higher than that of geocoded interferograms. However, the phase information would insignificantly degrade if an appropriate pixel spacing and geocoding algorithm are employed. Multiple unarranged interferograms observed from different directions can be geocoded into a common geographical grid. As the multiple geocoded interferograms on the common grid contain the offsets associated with the displacement lineaments at the same pixels, a single common path guide can be effectively and efficiently created from the multiple interferograms and can be utilized for the unwrapping of all the geocoded interferograms.

Visually identifying offsets from the interferometric phases, if not impossible, is difficult even for an expert because of the extraordinarily complicated phases. Fujiwara et al. (2016) employed conventional coherence computed from single-look complex images (Touzi et al. 1999; Hanssen 2001) to help identify offsets at instances when the coherence value decreases with an increase in the phase variance. Xu et al. (2020) utilized the phase gradients computed from the real and imaginary parts of a wrapped interferogram (Sandwell and Price 1998) combined with a low-pass filter, and stacking it to identify surface fractures caused by the 2019 Ridgecrest earthquake sequence. Here, a phase noise coherence estimate based on filtered interferometric phases was used, which was implemented in the GAMMA adf command (Werner et al. 2002; Lazecký et al. 2020). The amplitude of the filtered interferogram was set to 1 to avoid overestimating around pixels with a large amplitude. The window size was 5 pixels. The phase noise coherence estimate directly represents the noise level of the filtered phases to unwrap (Fig. 5), whereas conventional coherence does not always reflect it (Fig. 6).

The LOS offset amount in each interferogram differs depending on the LOS directions (i.e., incidence and azimuth angles), even though the ground displacement is the same. Therefore, some interferograms may exhibit a significant offset in a place, while others may not be in the same place. The average of the four phase noise coherence estimates reflects all offsets regardless of the LOS direction (Fig. 7a). A base of the common mask image that maps offsets caused by displacement lineaments was created by binarizing the average phase noise coherence estimate with a threshold of 0.9 (i.e., masked if the value is less than 0.9), which clearly displays the outlines of the displacement lineaments (Fig. 7b). As this image still has incomplete lines (i.e., disconnections along offsets), I manually added few masks to connect the incomplete lines, which was an uncomplicated task (Fig. 7c). The distribution of the line-like mask is consistent with the displacement lineaments identified by Fujiwara et al. (2016, 2020) (Fig. 7d). This crafted common mask image was utilized as an integration path guide to avoid crossing offsets in SNAPHU.

\section{Unwrapping error detection and correction using residuals}

Even though the reliable integration path guide derived in the previous section is implemented for unwrapping, unwrapping errors can still occur, especially in isolated components. Here, I detect and correct unwrapping errors using residuals from multiple interferograms.

As the three-dimensional (3D) ground deformation included in all interferograms is almost common, the projected LOS displacement in different interferograms with similar LOS directions should be comparable. In this case study, two interferograms observed from the west (i.e., descending left-looking and ascending right-looking) should have comparable LOS displacement, along with the two interferograms from the east (i.e., ascending leftlooking and descending right-looking). While the contribution of the difference in the incidence and azimuth angles and atmospheric noise exists, it should be mostly 


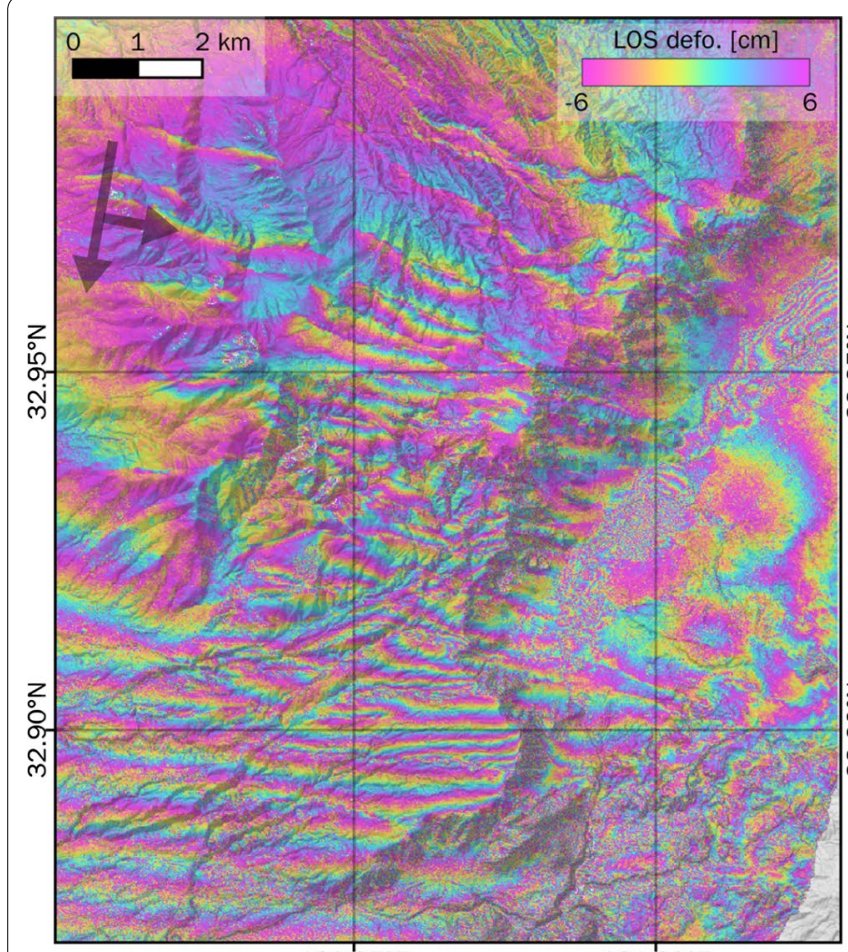

$130.95^{\circ} \mathrm{E}$ (a)

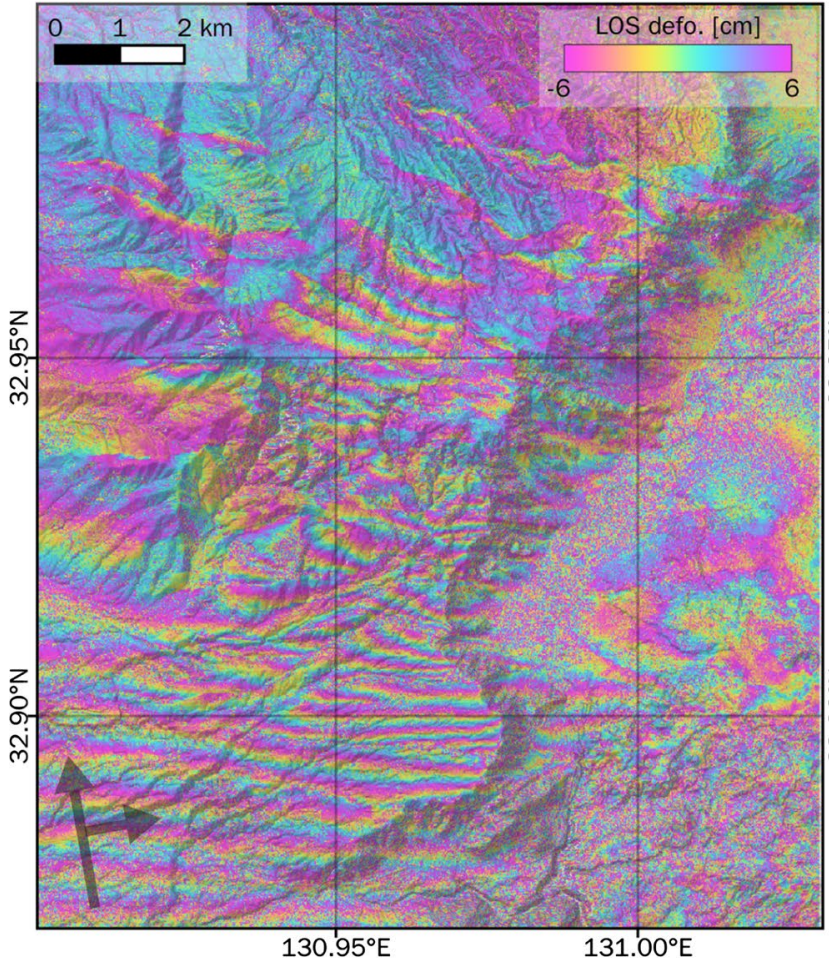

(c)

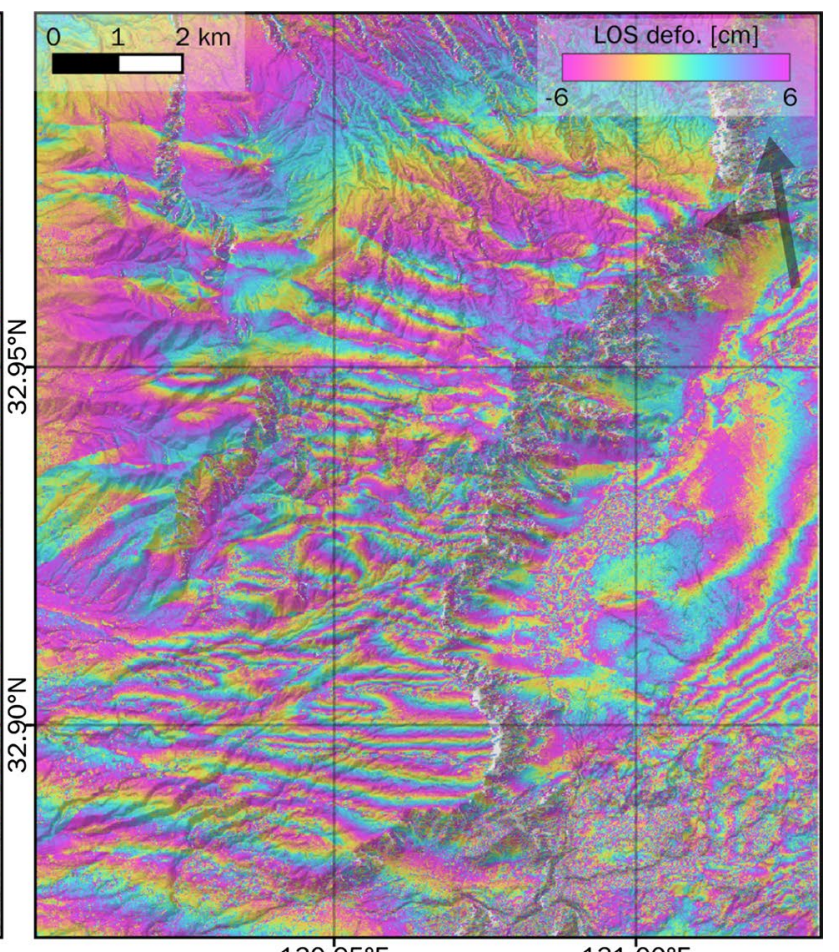

$130.95^{\circ} \mathrm{E}(\mathrm{b})$

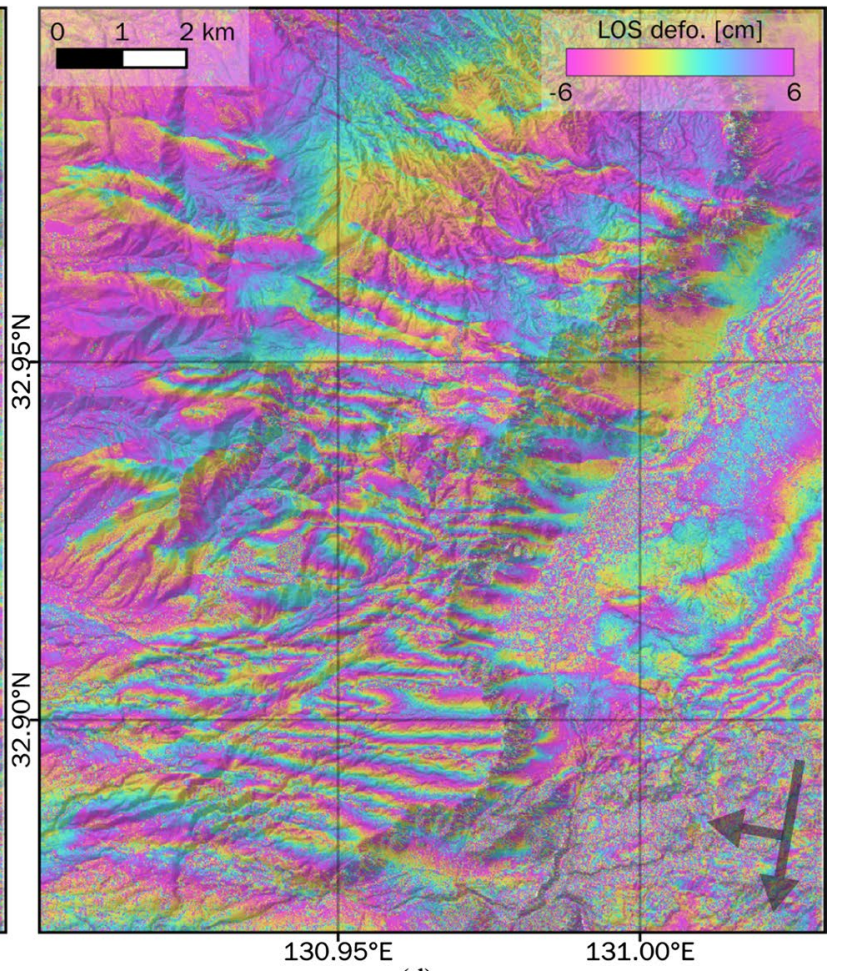

(d)

Fig. 2 Wrapped, unfiltered, and geocoded interferograms. a Descending left-looking. b Ascending left-looking. c Ascending right-looking. d Descending right-looking. For more detailed information on each interferogram, see Table 1 


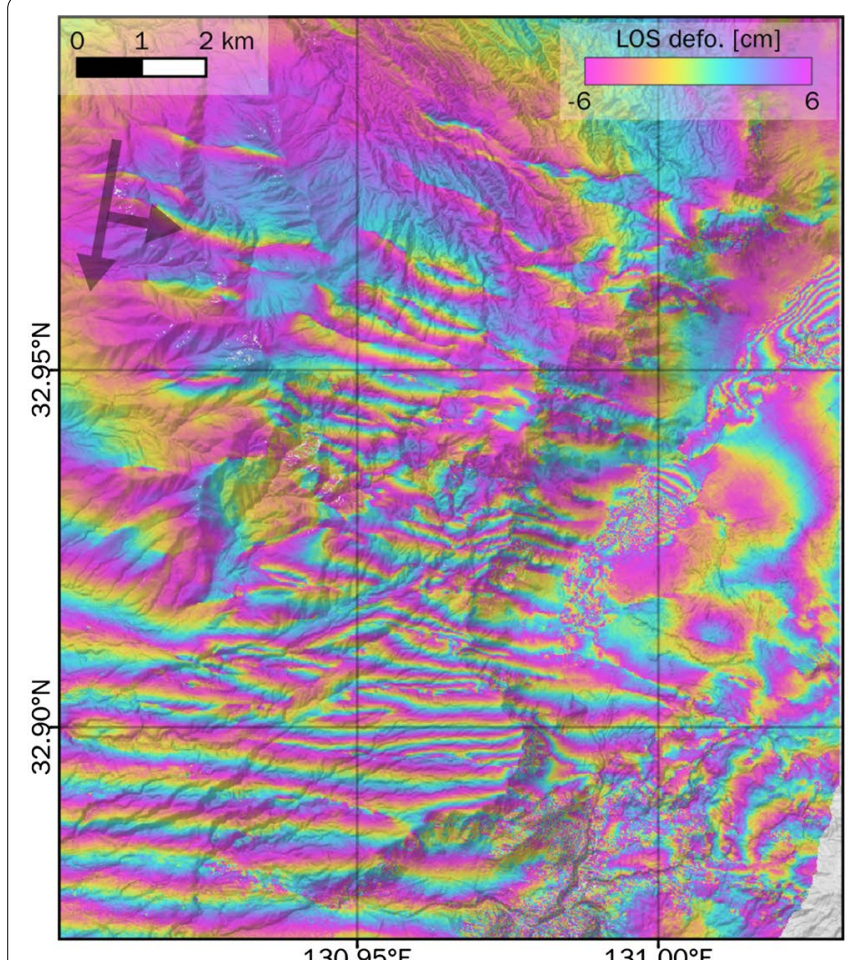

(a)

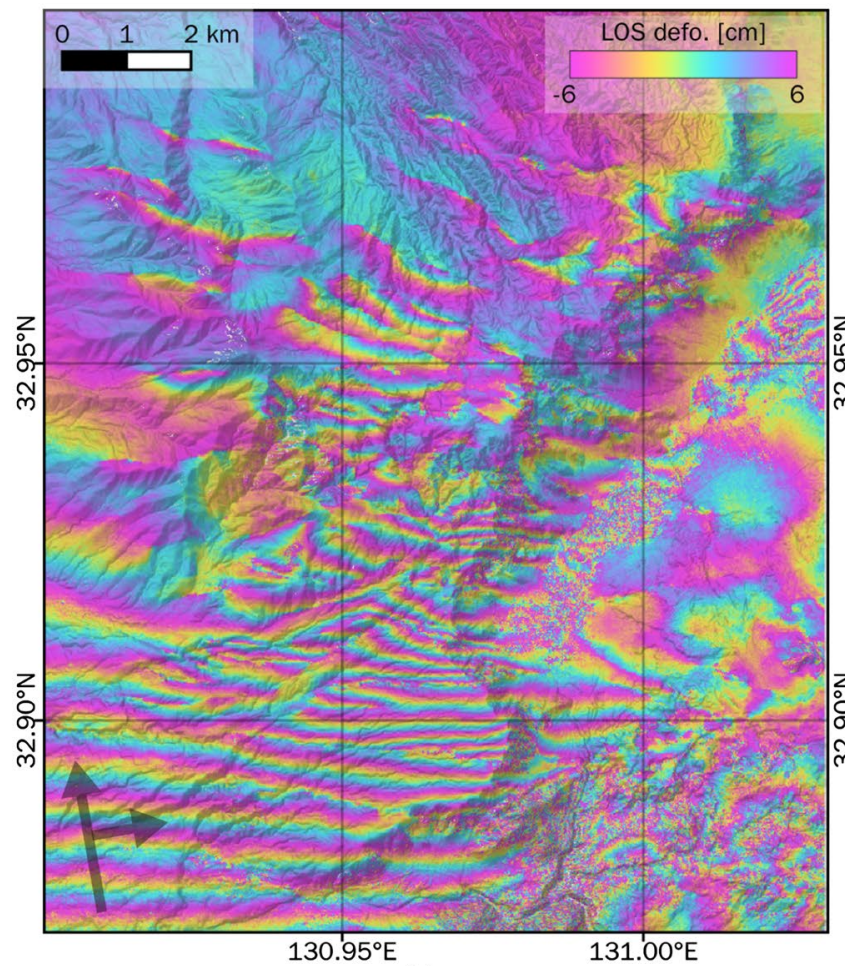

(c)

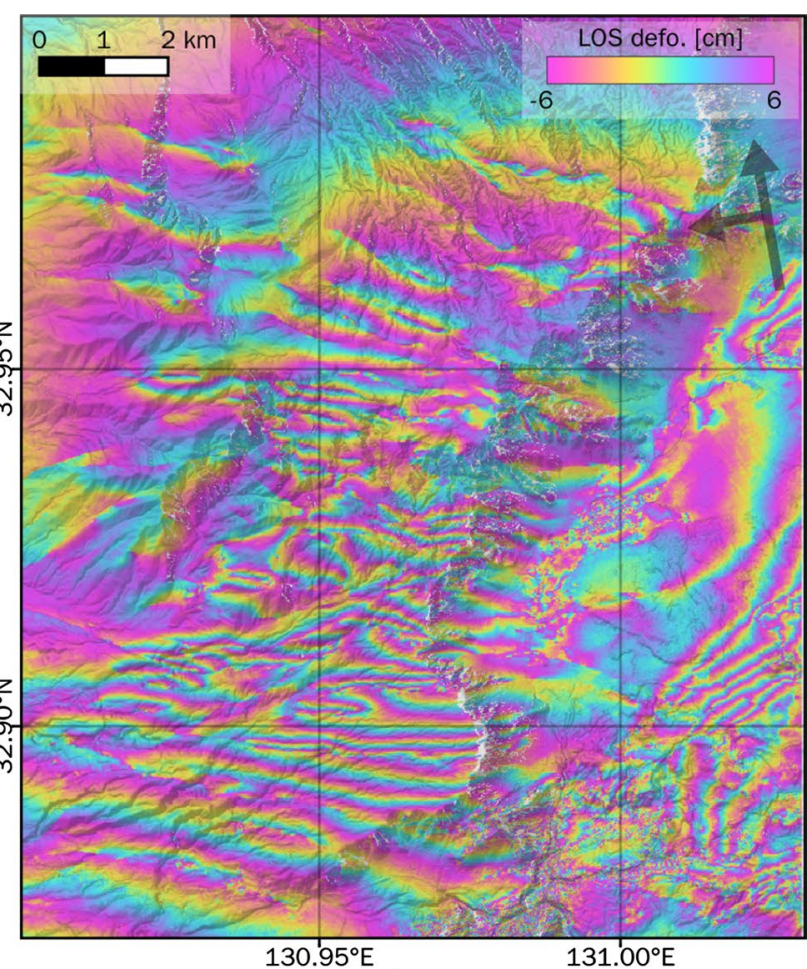

(b)

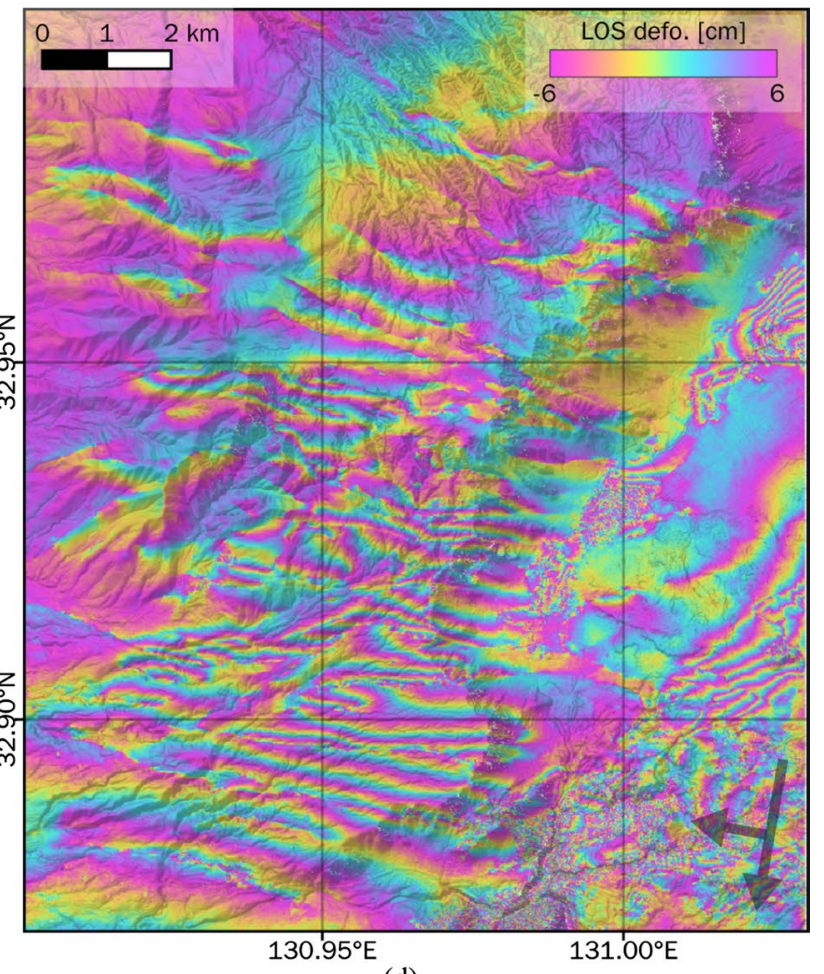

(d)

Fig. 3 Wrapped, filtered, and geocoded interferograms. a Descending left-looking. b Ascending left-looking. c Ascending right-looking. d Descending right-looking. For more detailed information on each interferogram, see Table 1 


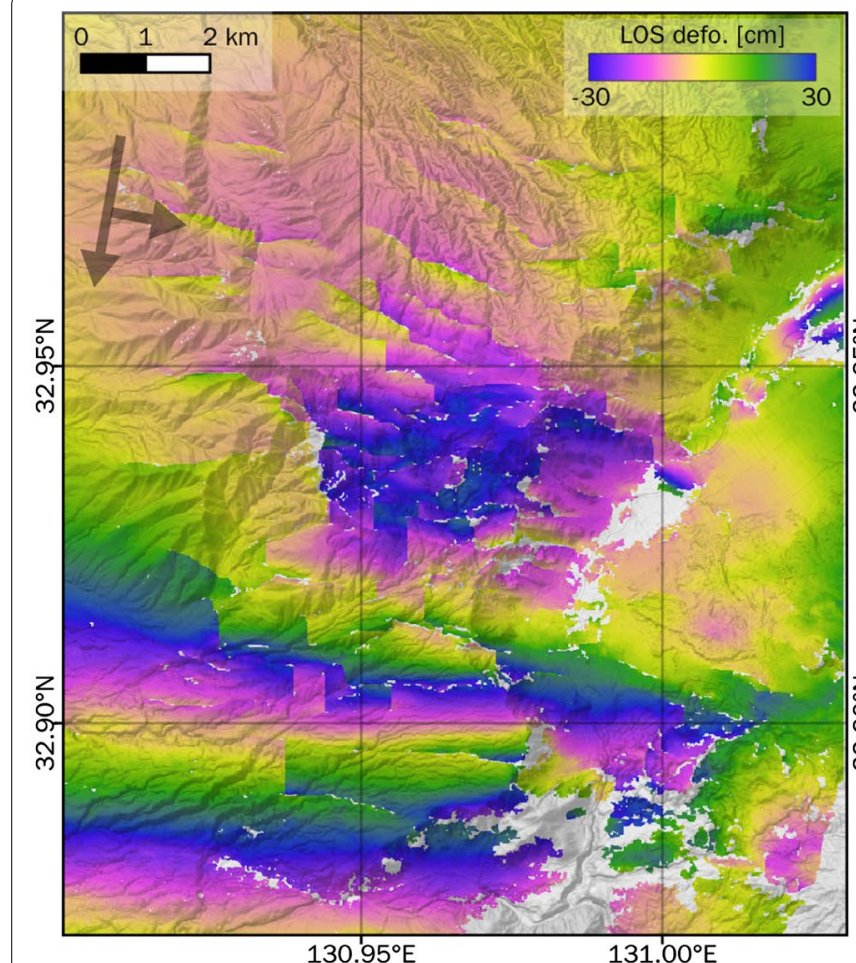

(a)

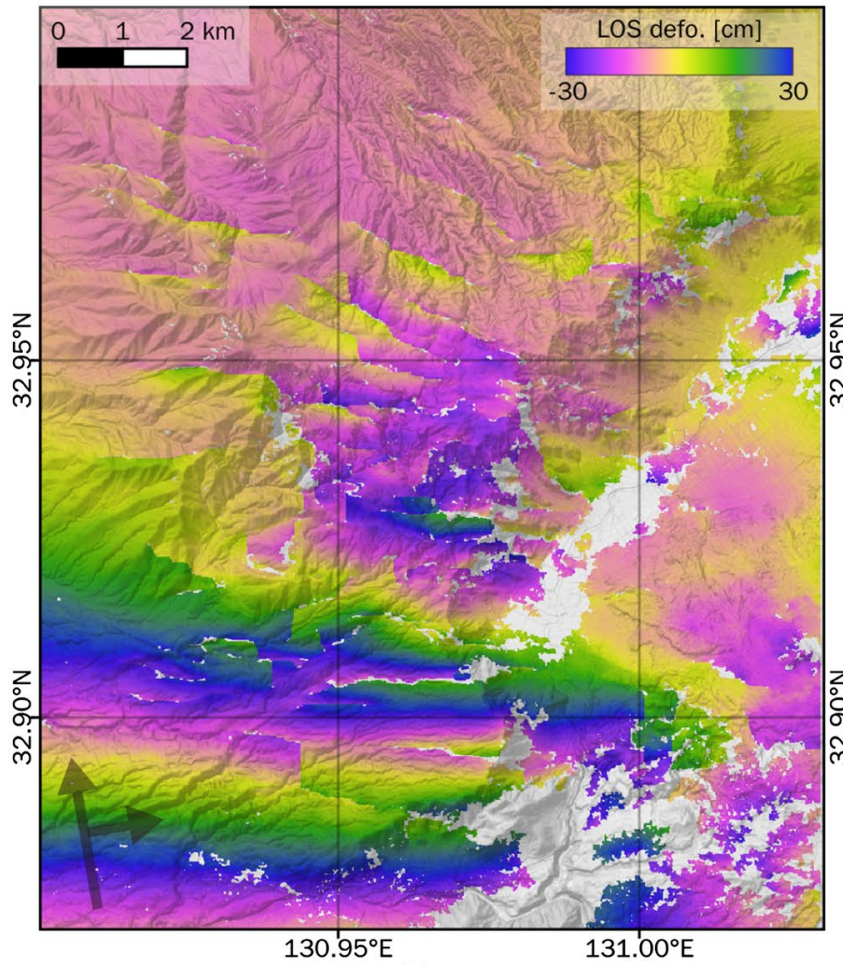

(c)

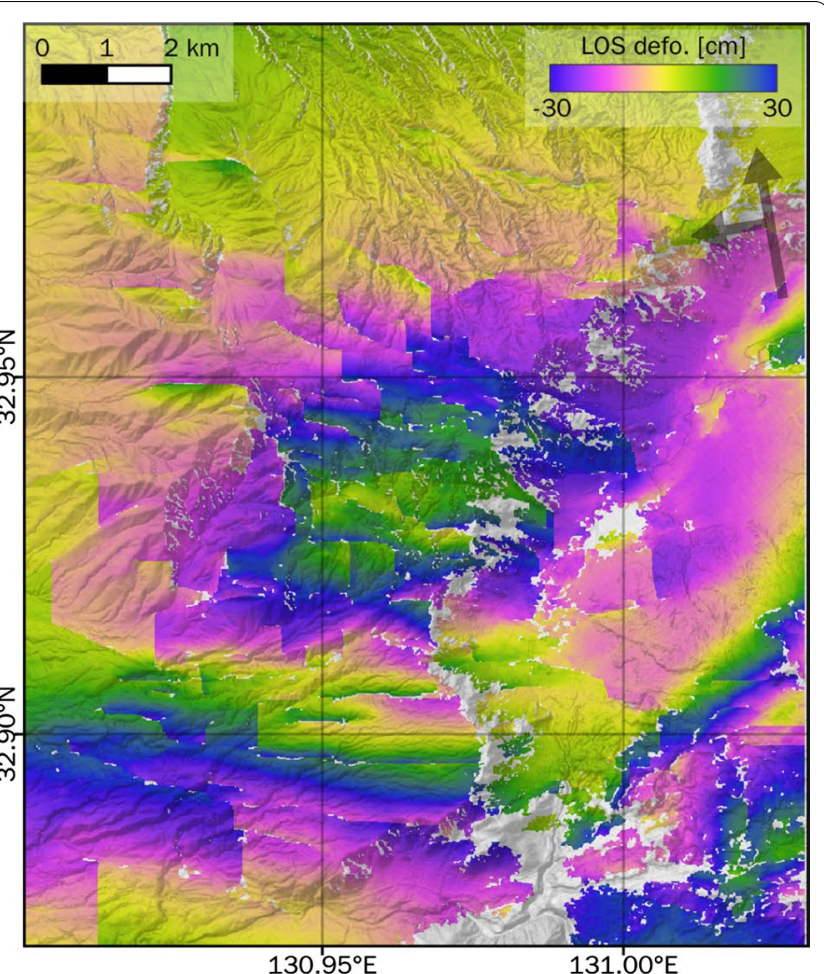

(b)

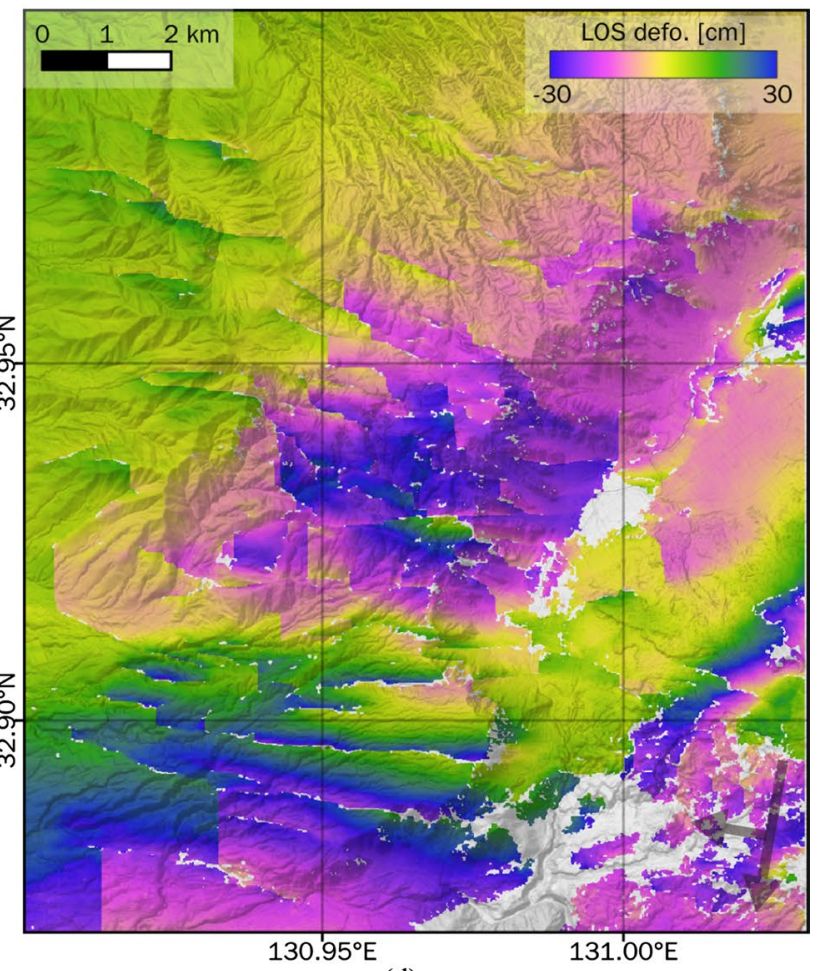

(d)

Fig. 4 Unwrapped phases using SNAPHU in a standard way. The data are rewrapped to $60 \mathrm{~cm} / \mathrm{cycle}(\sim 10 \pi$ radian/cycle) to visualize unwrapping errors. a Descending left-looking. b Ascending left-looking. c Ascending right-looking. d Descending right-looking 


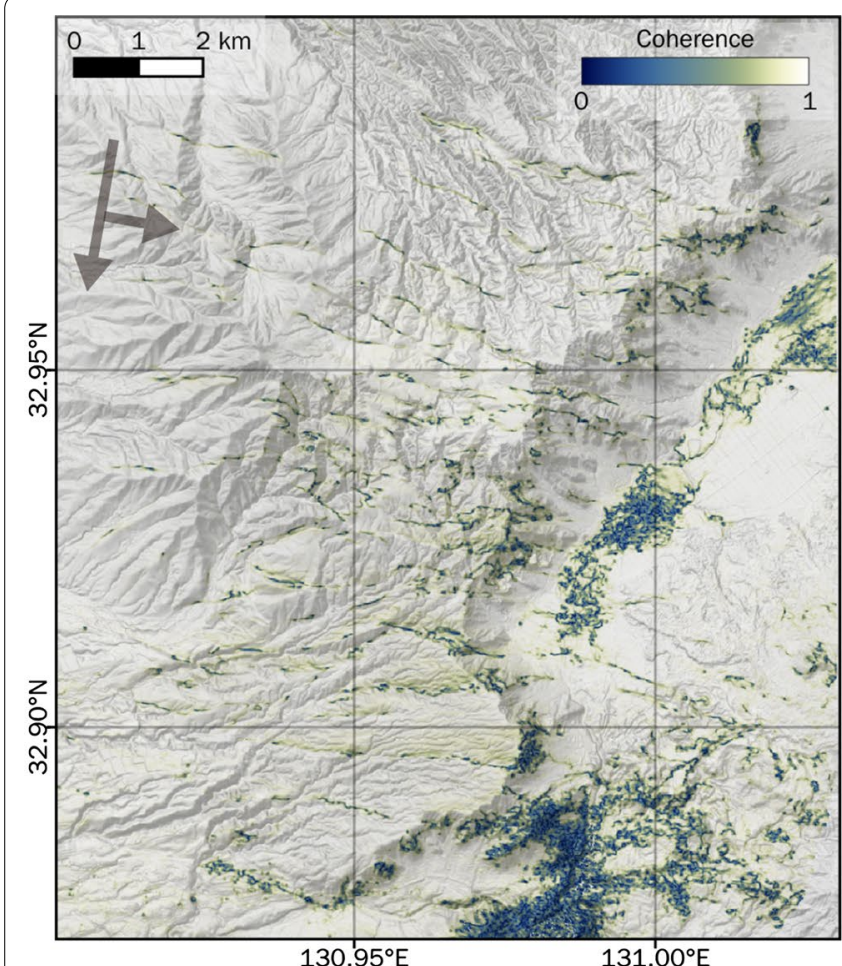

(a)

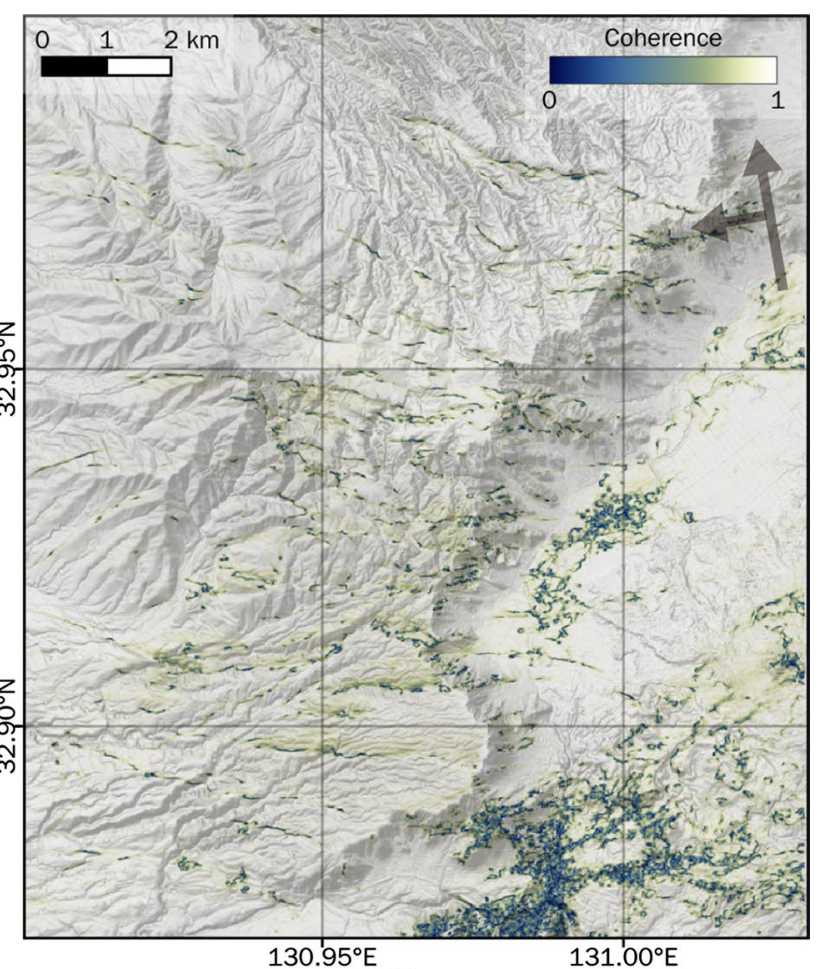

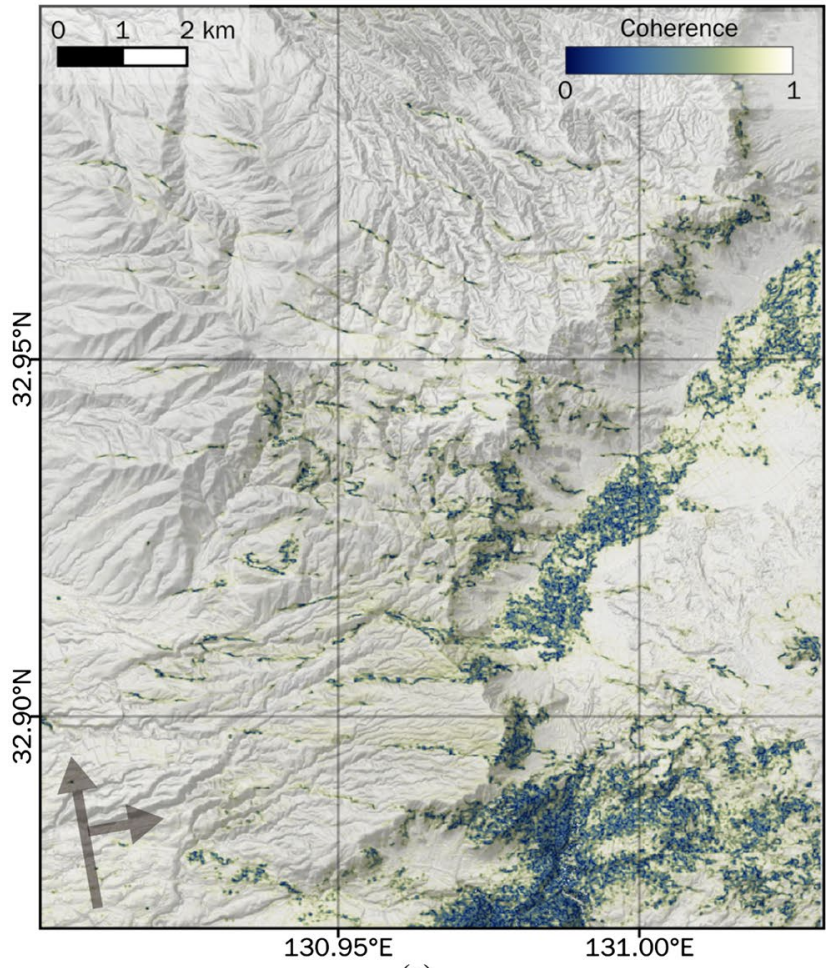

(c) (b)

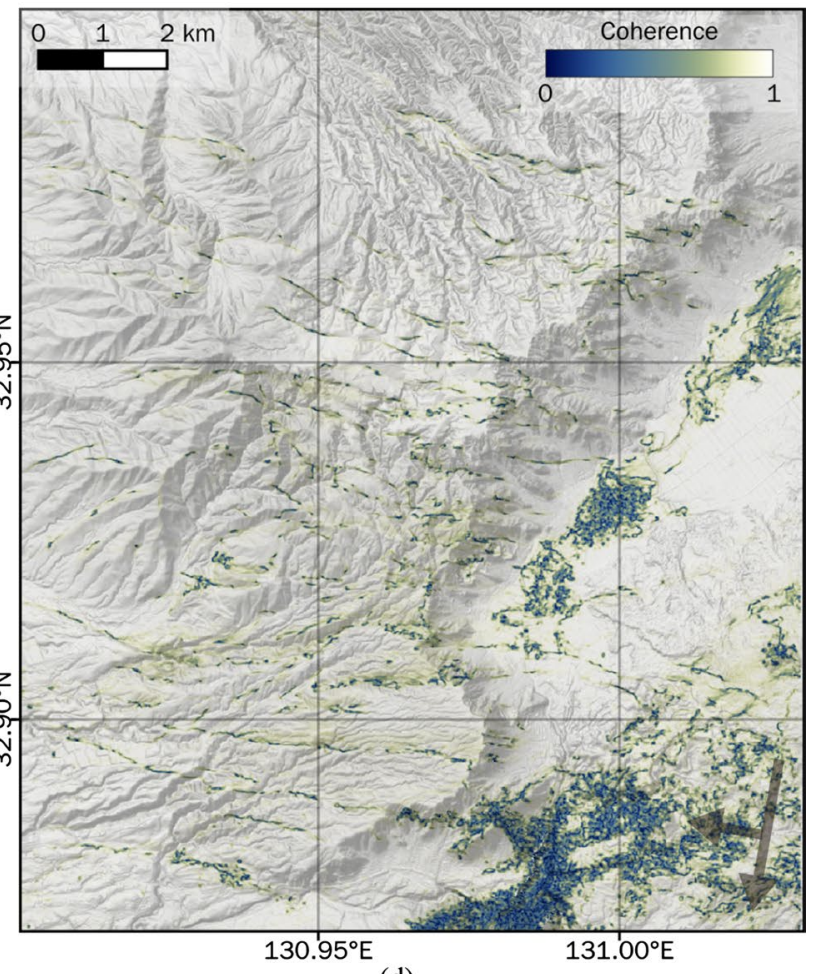

(d)

Fig. 5 Phase noise coherence estimate. a Descending left-looking. b Ascending left-looking. c Ascending right-looking. d Descending right-looking 


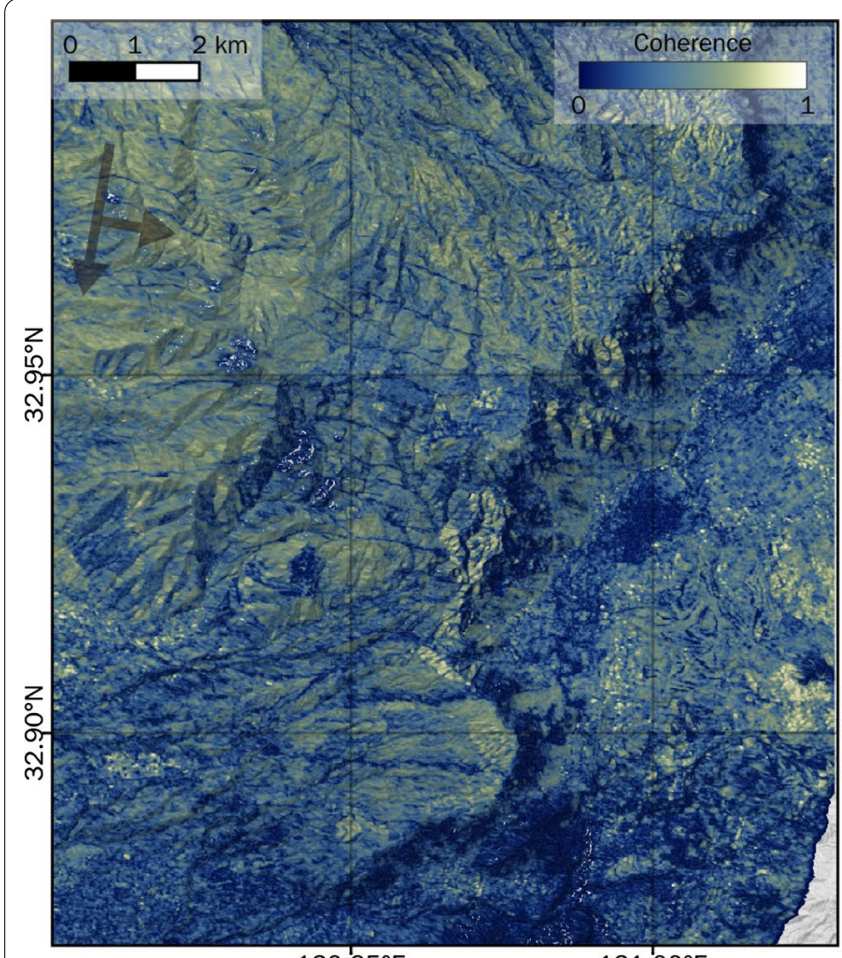

$130.95^{\circ} \mathrm{E}$ (a)

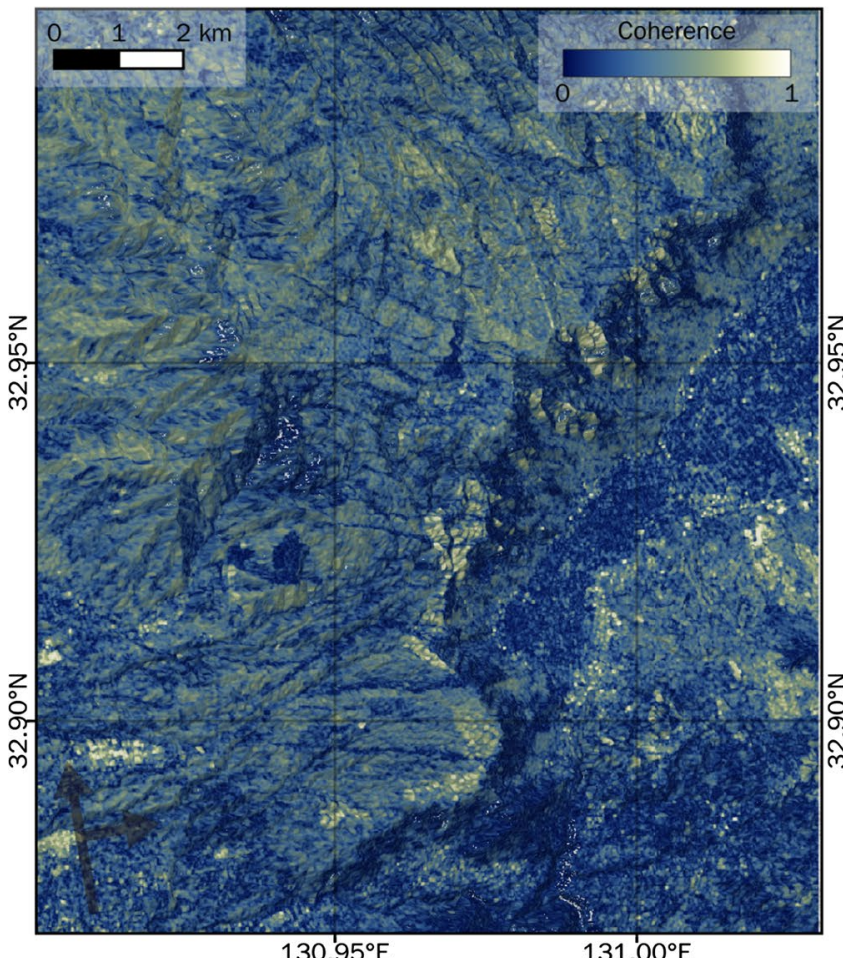

(c)

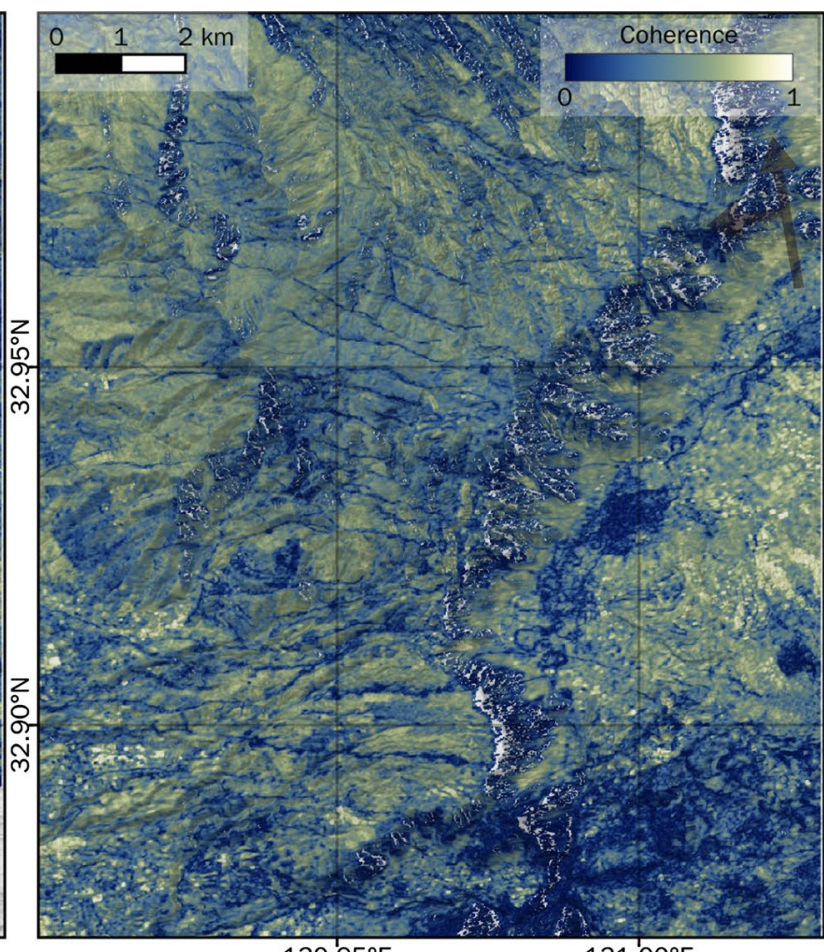

$130.95^{\circ} \mathrm{E}$ (b)

(b)

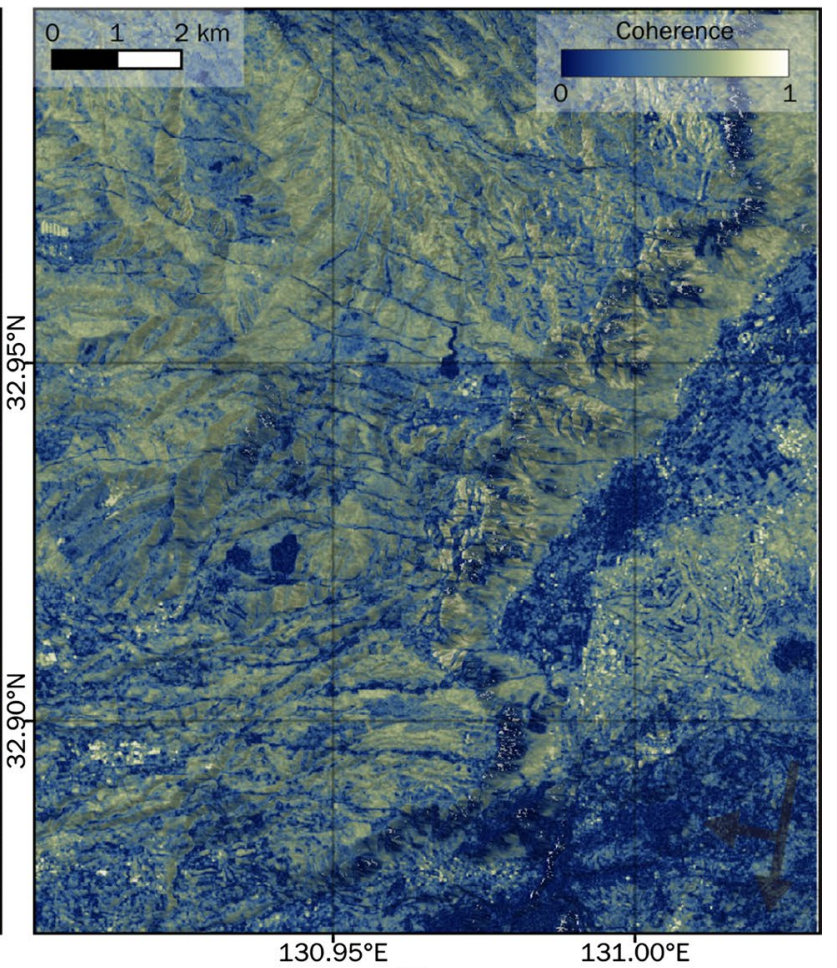

(d)

Fig. 6 Conventional coherence. a Descending left-looking. b Ascending left-looking. c Ascending right-looking. d Descending right-looking 


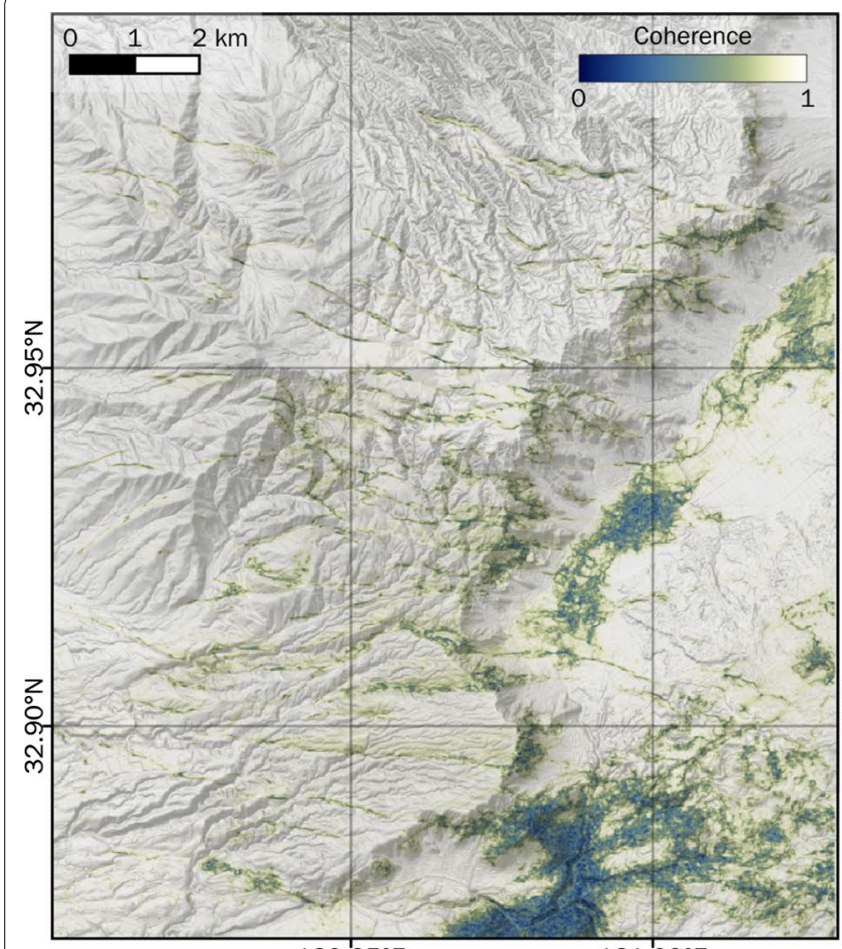

(a)

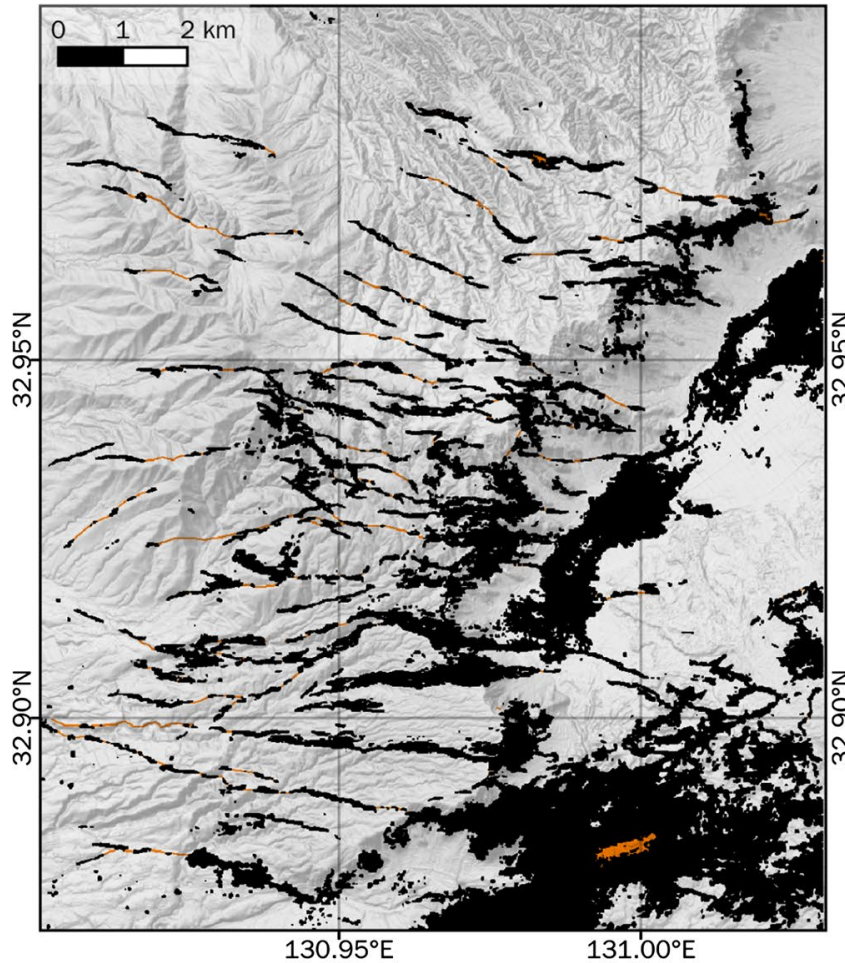

(c)

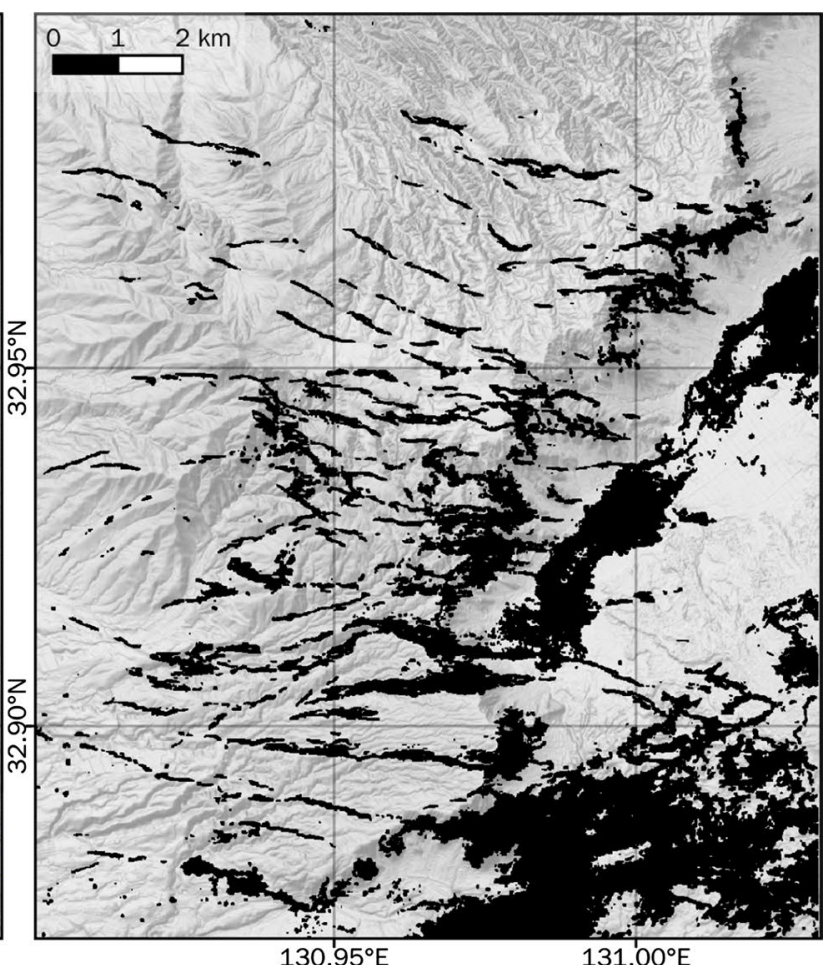

(b)

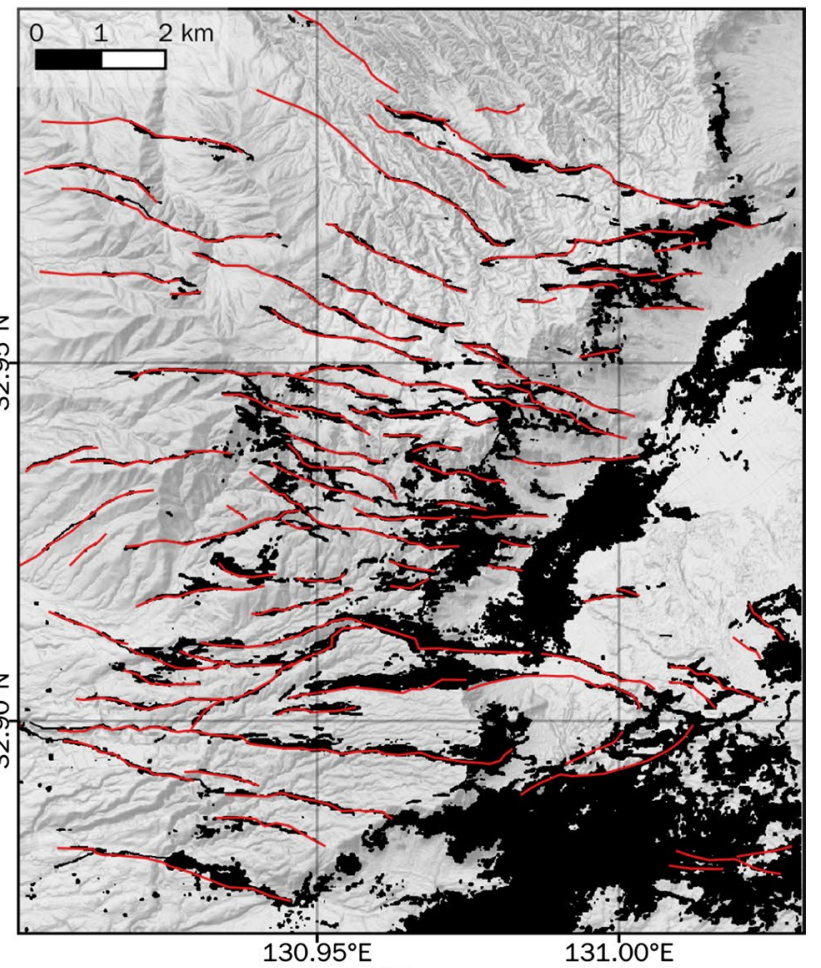

(d)

Fig. 7 a Average phase noise coherence estimate. b Base of the common mask image. Black pixels are masked. c Crafted common mask image. The manually added mask is highlighted by orange color. $\mathbf{d}$ Crafted common mask image overlaid by the displacement lineaments (red lines) identified by Fujiwara et al. $(2016,2020)$ 
smaller than the unwrapping error $(\sim 12 \mathrm{~cm}$ in this case), or smooth signals must exist that are distinguishable from the unwrapping errors. The difference (residual) of the preliminary unwrapped phases between the two interferograms clearly exhibits unwrapping errors in few isolated components (Fig. 8a, c). SNAPHU can output a connected component file that contains identification numbers for each isolated component (Chen and Zebker 2002; Yunjun et al. 2019). The unwrapping errors can be corrected by manually adding $\pm 2 \pi \times \mathrm{n}$ into the components with suspected unwrapping errors to produce small and smooth residual (Fig. 8b, d). As a result, reliable unwrapped phases are obtained (Fig. 9). Some components in the caldera floor (the lower right part in the image) are not corrected, because they are irrelevant to the displacement lineaments.

Even if left-looking observations are not available, different from this study, this unwrapping error detection approach is feasible if multiple independent interferograms containing comparable LOS displacements are available (e.g., in adjacent paths with different incidence angles, or with the same path and incidence angle but on different acquisition dates). Redundancy increases the reliability of unwrapping results.

Another possible approach to detect the unwrapping error is to implement residuals from 3D decomposition utilizing four different LOS directions (Morishita et al. 2016). An unwrapping error ( $12 \mathrm{~cm}$ in L-band) in an interferogram leads to more than a few centimeters residuals in all interferograms (Fig. 10a-d), while $\sim 2 \mathrm{~cm}$ smooth residuals remain because of independent atmospheric noise. After correcting for the unwrapping errors, the characteristic residuals disappeared (Fig. 10e-h).
While the residuals highlight the candidates of interferograms and components therein with unwrapping errors, the exact interferogram including the error cannot be uniquely identified from the residuals and hence needs to be empirically determined, for example, from phase continuity from surrounding pixels.

If the same unwrapping errors are accidentally included in the same components of multiple interferograms from similar LOS directions (either just after automatic unwrapping processing or by a false unwrapping error correction), the errors are canceled out and remain undetected in the residual. However, in that case, decomposed (i.e., horizontal and vertical) displacements using different LOS directions directly reflects the errors and could be a clue to detect the errors. An unwrapping error of $12 \mathrm{~cm}$ in the LOS direction would result in an error of at least $\sim 8 \mathrm{~cm}$ in the east-west or up-down directions depending on the incidence angle, although it might be difficult to distinguish this type of error from the true displacements.

Similar approaches to detect and correct unwrapping errors exploiting loop phase closure were developed (Biggs et al. 2007; Yunjun et al. 2019; Morishita et al. 2020; Oliver-Cabrera et al. 2021). The difference of the proposed approach from the above-mentioned approaches is the exploiting interferograms observed from different LOS directions (i.e., containing different LOS displacements projected from the same displacement field). The identical LOS displacements in multiple interferograms lead to similar difficulties in unwrapping and, therefore, may result in the same unwrapping errors which are undetectable. However, different LOS displacements in multiple interferograms bring different difficulties in unwrapping (i.e., success in an interferogram,

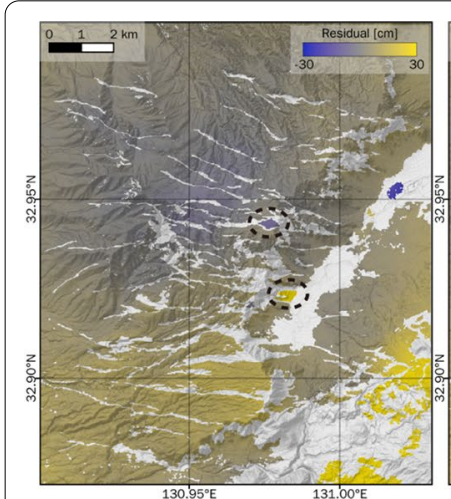

(a)

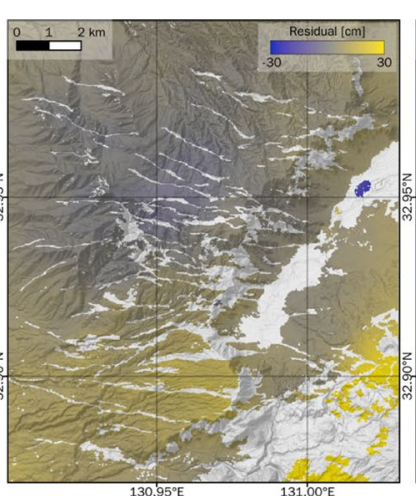

(b)

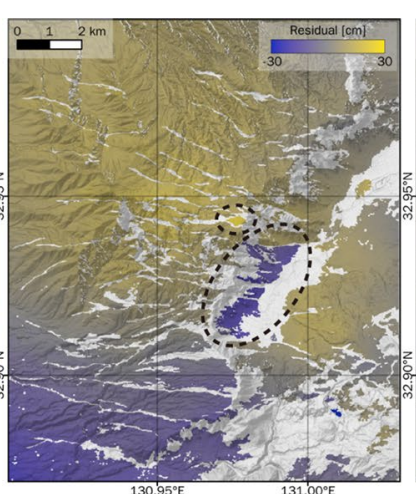

(c)

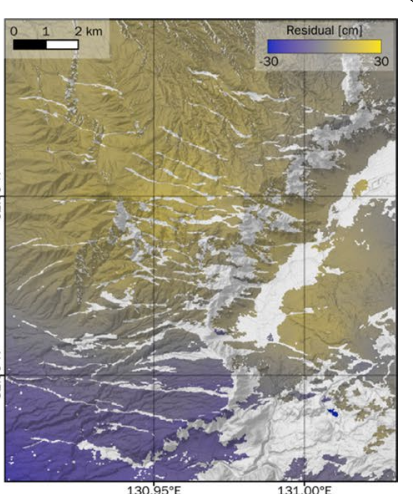

(d)

Fig. 8 Residuals between unwrapped phases with similar LOS directions. a Observed from the west (i.e., descending left-looking and ascending right-looking) before unwrapping error corrections. Ellipses with black dashed lines denote isolated components containing unwrapping errors. $\mathbf{b}$ Observed from the west after corrections. c Observed from the east (i.e., ascending left-looking and descending right-looking) before corrections. Ellipses with black dashed lines denote isolated components containing unwrapping errors. $\mathbf{d}$ Observed from the east after corrections 


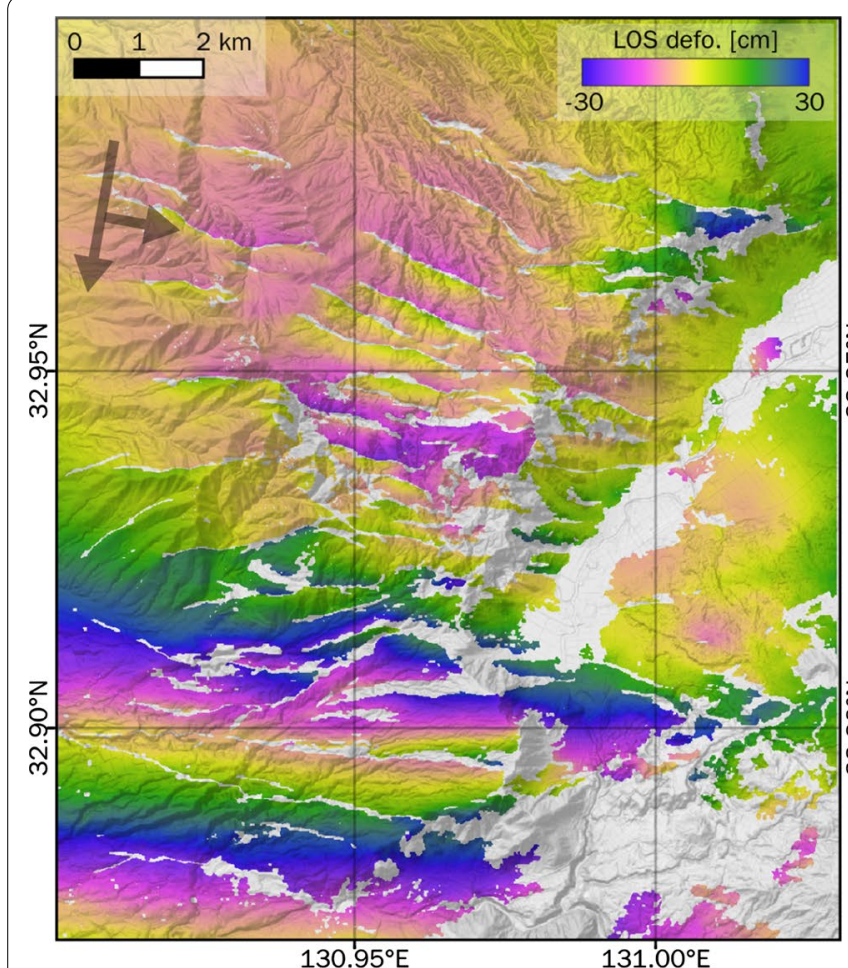

(a)

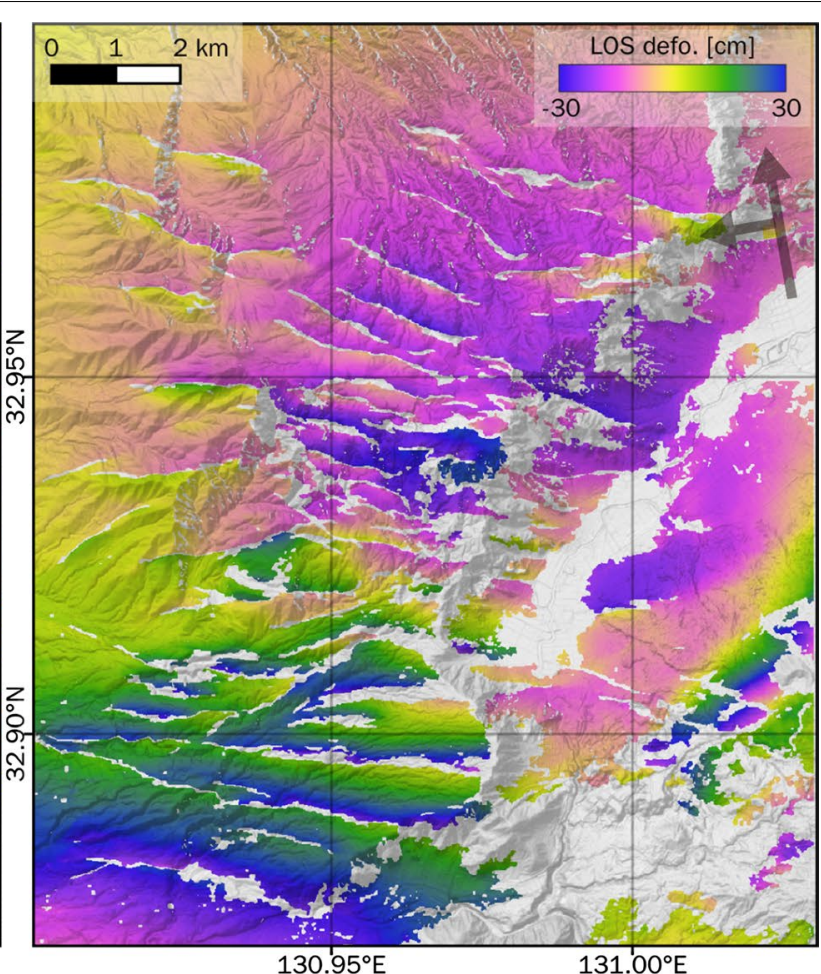

(b)

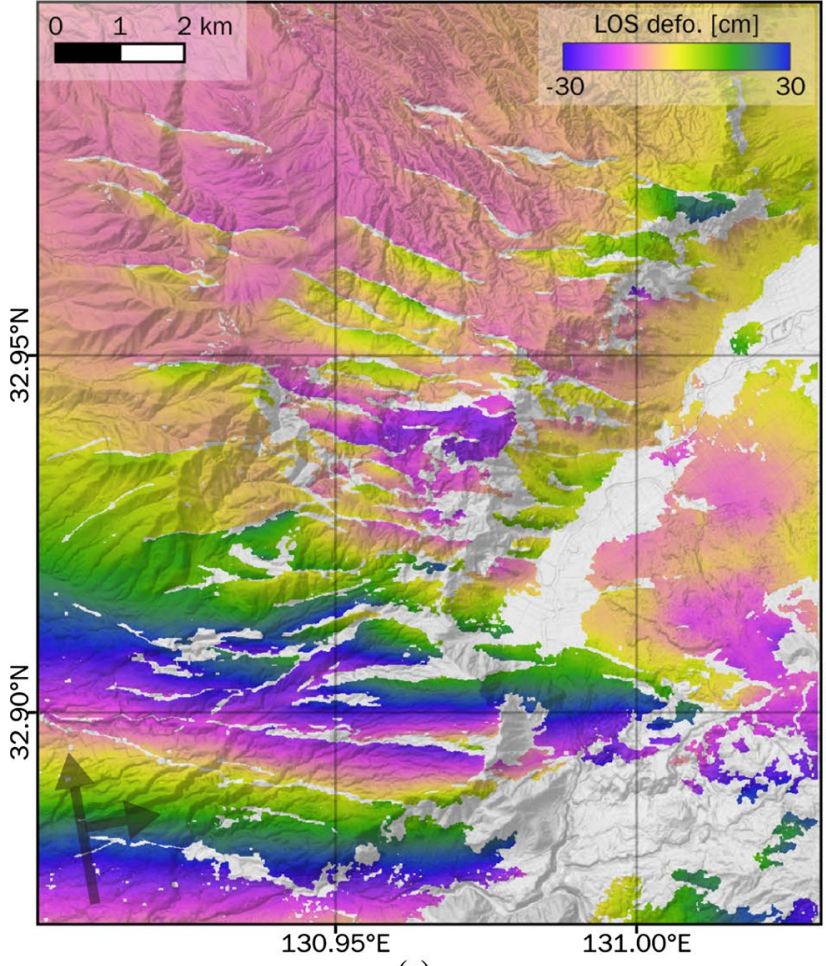

(c)

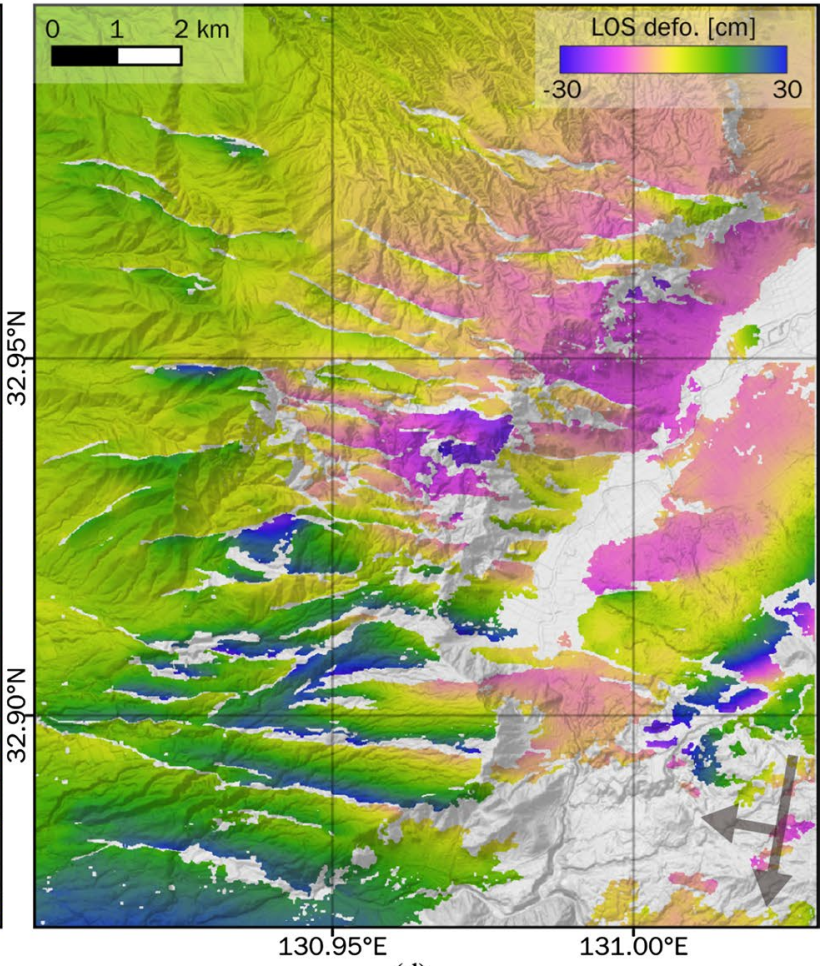

(d)

Fig. 9 Unwrapped phases using the proposed approach. The data are rewrapped to $60 \mathrm{~cm} / \mathrm{cycle}(\sim 10 \pi$ radian/cycle) to visualize unwrapping errors. a Descending left-looking. b Ascending left-looking. c Ascending right-looking. d Descending right-looking 


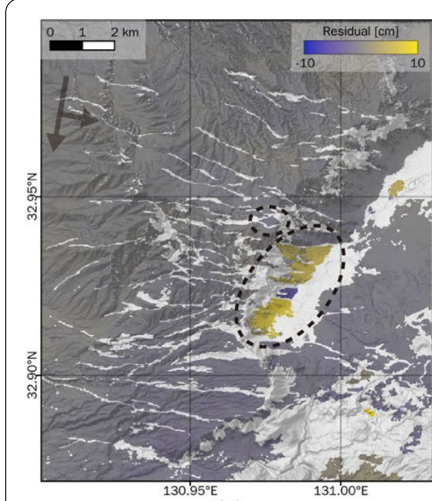

(a)

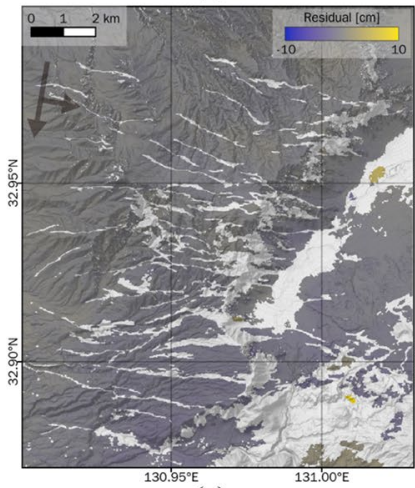

(e)

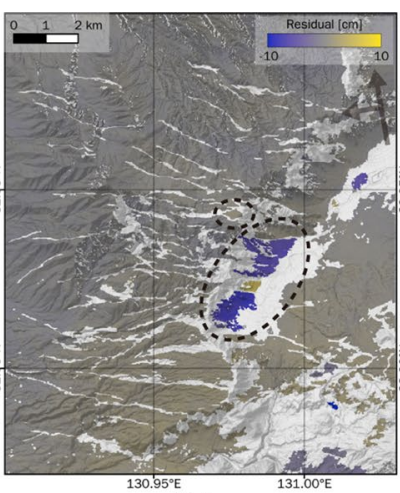

(b)

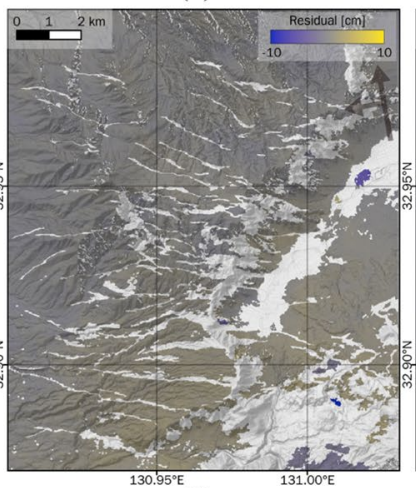

(f)

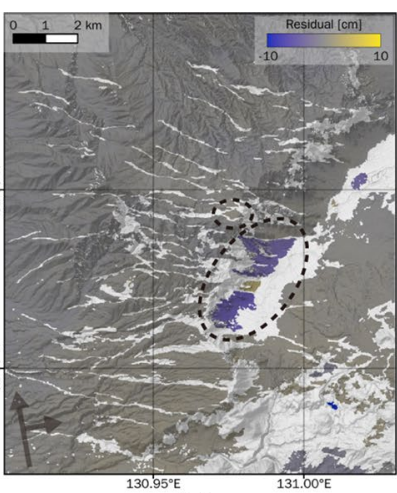

(c)

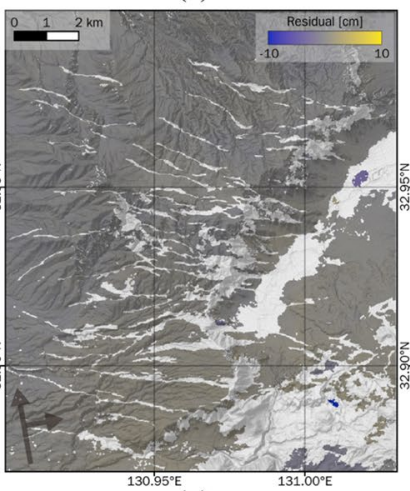

(g)

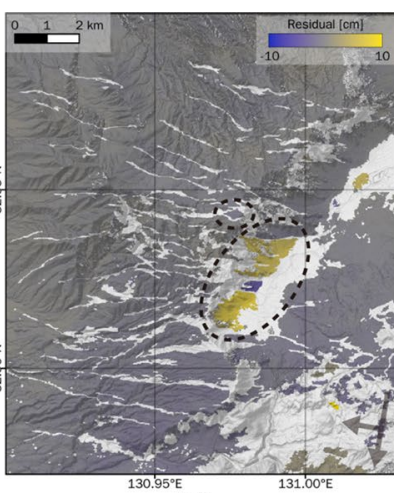

(d)

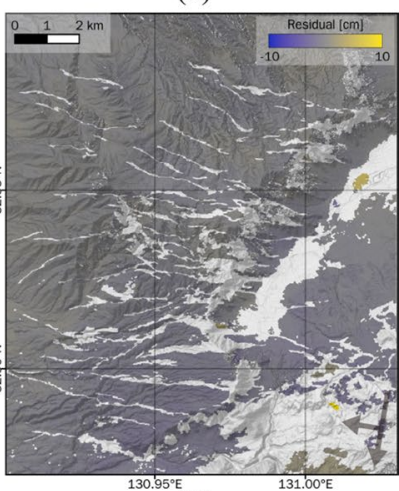

(h)

Fig. 10 Residuals from the 3D decomposition. a-d Before unwrapping error corrections. e-h After unwrapping error corrections. Ellipses with black dashed lines in $\mathbf{a}-\mathbf{d}$ denote isolated components containing unwrapping errors. $\mathbf{a}, \mathbf{e}$ Descending left-looking. $\mathbf{b}, \mathbf{f}$ Ascending left-looking. $\mathbf{c}, \mathbf{g}$ Ascending right-looking. $\mathbf{d}, \mathbf{h}$ Descending right-looking

failure in another one), enhancing the chance to detect and correct the unwrapping errors induced from complicated deformation.

\section{Three-dimensional deformation derived from unwrapped interferograms}

I derived the 3D displacements from the corrected unwrapping results of four interferograms (Morishita et al. 2016; Fig. $11 \mathrm{a}-\mathrm{c}$ ). Pixels with $>2 \mathrm{~cm}$ root-meansquare of the residuals (i.e., still including unwrapping errors in the caldera floor) were masked. To isolate small deformations associated with displacement lineaments from large coseismic deformation caused by the seismogenic faults, a Gaussian low-pass filter with a $\sigma$ of $1 \mathrm{~km}$ was applied to each component of the 3D deformation (Fig. 11d-f). The remaining high-pass component of the 3D deformation (Fig. 11g-i) is consistent with Fujiwara et al. $(2016,2020)$ and leads to the following interpretations. Most lineaments have dip-slip components. The patterns of the vertical offsets are roughly divided into two groups: south side up in the south and south side down in the north, corresponding to half-graben and graben formations. For more detailed interpretations, please refer to Fujiwara et al. $(2016,2020)$.

\section{General applicability of the proposed method}

The proposed method needs multiple interferograms observed from different LOS directions, containing consistent deformation with sufficient coherence. The method cannot be applied in decorrelated areas with too large deformation gradient, often seen around seismogenic faults, to sustain coherence. Hence, a long wavelength (i.e., L-band rather than C- and X-band), high spatial resolution (wide bandwidth), and short temporal baselines are important for this method. Although the available L-band SAR data are currently quite limited, next-generation satellites such as ALOS-4 and NASAISRO SAR (NISAR) will provide abundant high-quality L-band SAR data and enhance the opportunity of this proposed method (Motohka et al. 2019, 2020; Jet Propulsion Laboratory 2020). Recent studies have reported several cases of complicated displacement lineaments 


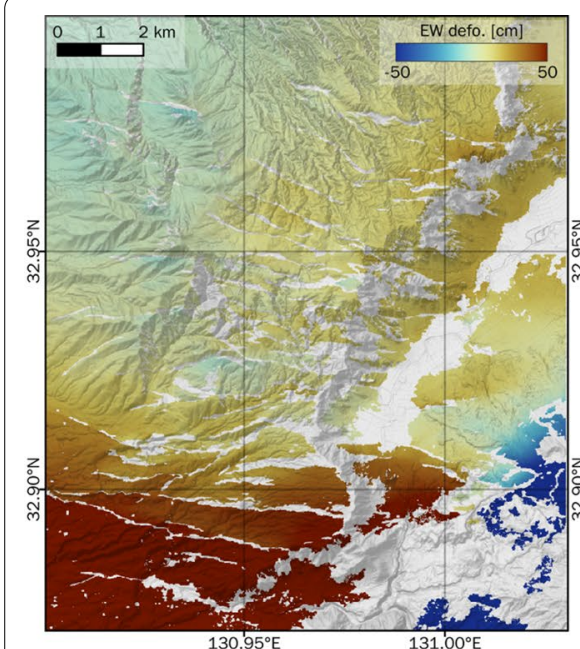

(a)

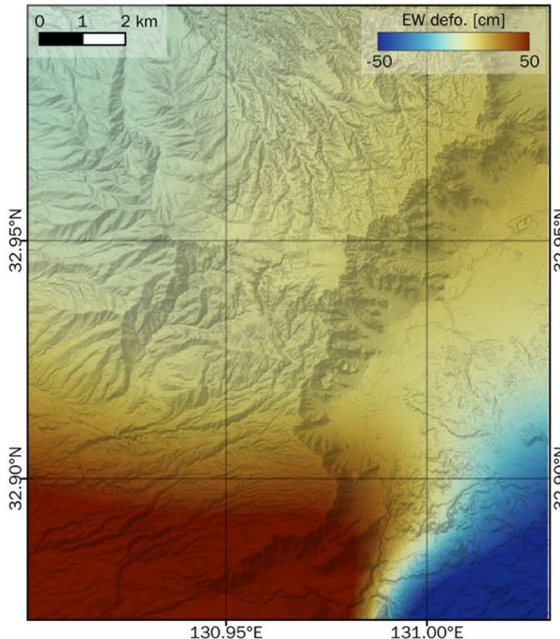

(d)

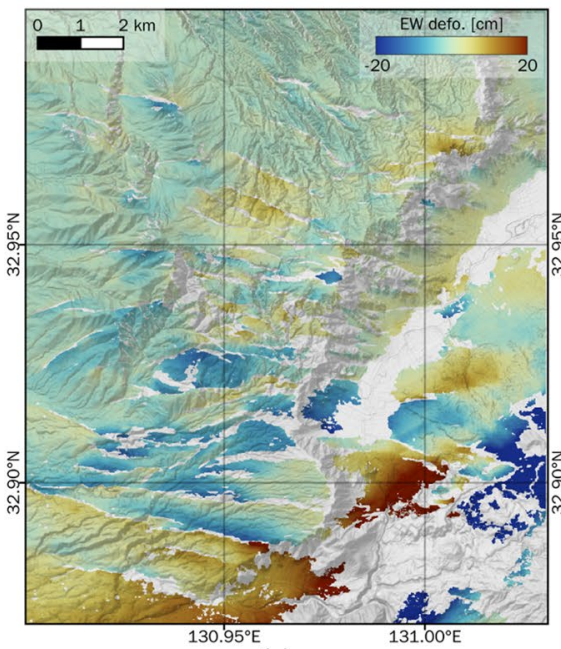

(g)

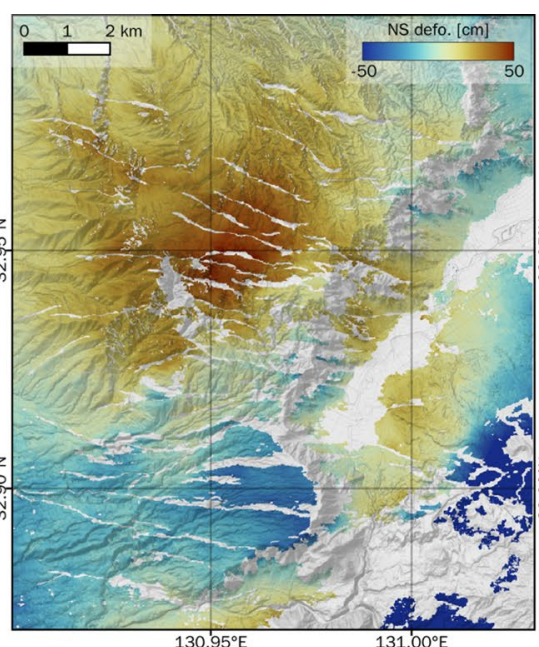

(b)

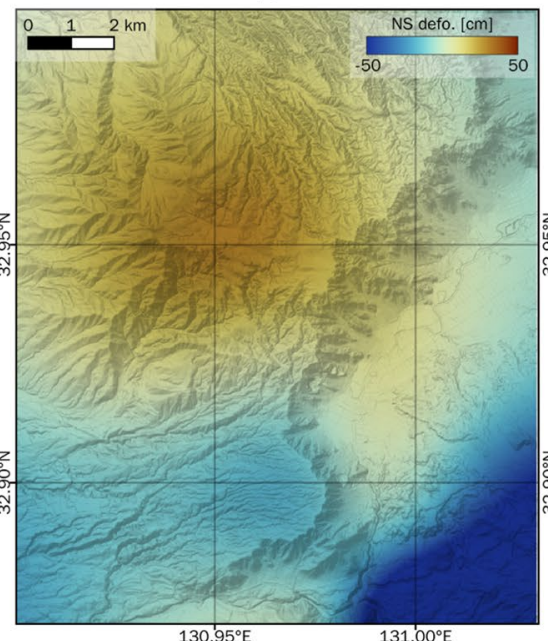

(e)

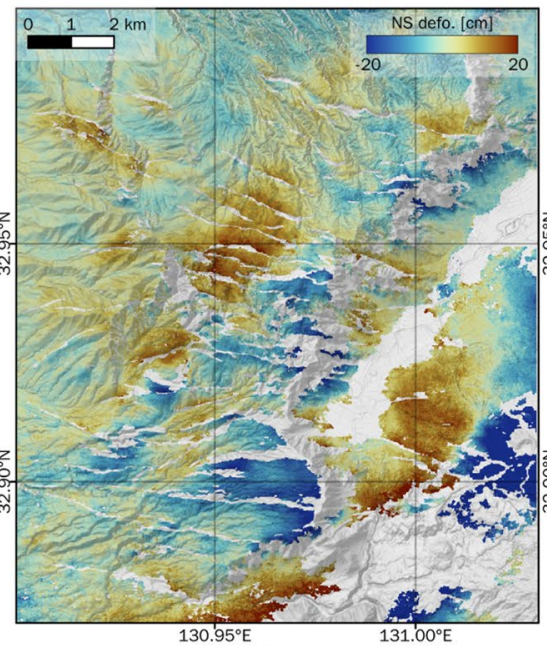

(h)

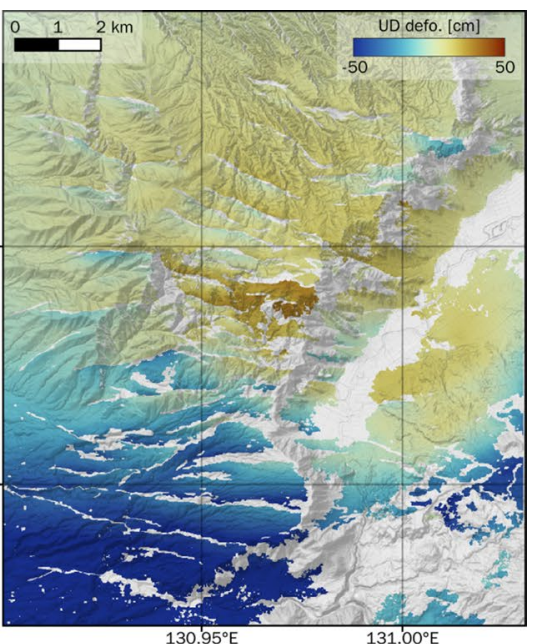

(c)

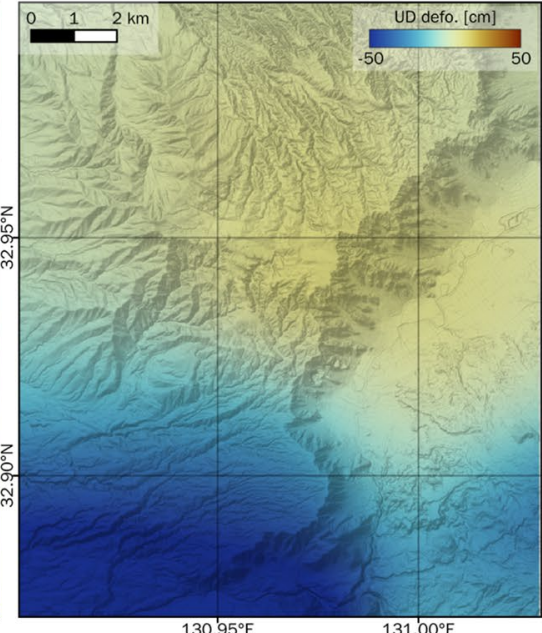

(f)

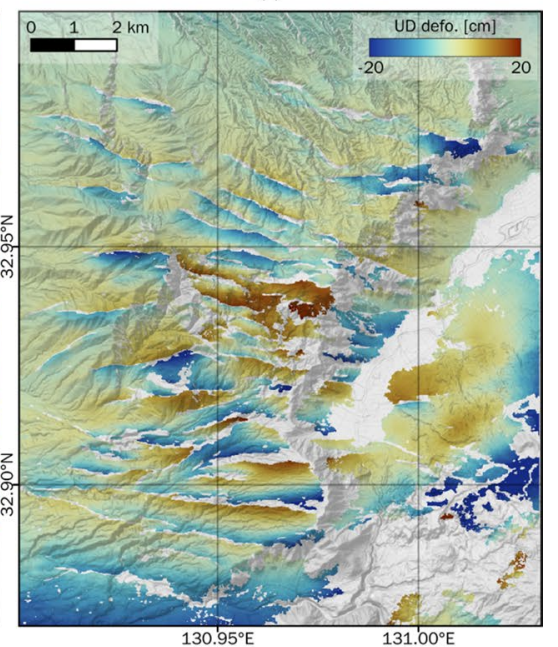

(i)

Fig. $113 D$ deformation derived from the corrected unwrapping results. a-c Original. $\mathbf{d}-\mathbf{f}$ Low-pass component by the Gaussian filter. $\mathbf{g}-\mathbf{i}$ High-pass component. a, d, $\mathbf{g}$ East-west component. beh North-south component. c, f, i Up-down component 
triggered by large earthquakes (Morishita et al. 2018; $\mathrm{Xu}$ et al. 2020; Fujiwara et al. 2020); however, they are not as complicated as the 2016 Kumamoto earthquake and the condition (i.e., spatial resolution and temporal baselines) of the available SAR data are poorer than the 2016 Kumamoto earthquake. The proposed method will be applicable to future large earthquakes that trigger remarkably complicated displacement lineaments with abundant L-band SAR data.

\section{Conclusions}

An effective unwrapping method for remarkably complicated phases was proposed in this study that exploited multiple geocoded interferograms and their phase noise coherence estimates to create a common path guide effectively and efficiently, followed by uncomplicated manual adjustments. The remaining unwrapping errors can be detected from the residuals of the unwrapped phases between independent interferograms with similar LOS directions and can be corrected by adding $\pm 2 \pi \times n$ to each isolated component. A case study using ALOS-2 data in the northwest of the outer rim of the Aso caldera, where remarkably complicated displacement lineaments were generated by the 2016 Kumamoto earthquake, demonstrated that reliable unwrapped phases were obtained by the proposed approach which led to significant findings and interpretations. This approach may help reveal details of complicated deformation by InSAR and unrecognized mechanisms in future earthquakes or other deformation-causing geophysical phenomena.

\section{Abbreviations \\ 3D: Three-dimensional; ALOS: Advanced land observing satellite; DEM: Digital elevation model; GSI: Geospatial Information Authority of Japan; InSAR: Interferometric synthetic aperture radar; JAXA: Japan Aerospace Exploration Agency; JMA: Japan Meteorological Agency; LOS: Line-of-sight; Mj: Japan meteorological agency magnitude; NISAR: NASA-ISRO SAR; SAR: Synthetic aperture radar; SNAPHU: Statistical-cost, network-flow algorithm for phase unwrapping.}

\section{Acknowledgements}

ALOS-2 data were provided by the Earthquake Working Group under a cooperative research contract between the GSI and the Japan Aerospace Exploration Agency (JAXA). JAXA holds full ownership of the ALOS-2 data set. The products of the numerical weather model were provided by the JMA under the agreement between GSI and JMA. The DEM data were available from the GSI website (https://fgd.gsi.go.jp/download/ref_dem.html). The background maps used in all the figures were obtained from the GSI Tiles (https://maps.gsi. go.jp/development/ichiran.html).

\section{Authors' contributions}

YM planned and designed the work, developed the approach, analyzed the data, drafted the manuscript. The author read and approved the final manuscript.

\section{Funding}

This work was supported by GSI (Geospatial Information Authority of Japan).
Availability of data and materials

The data sets used and/or analyzed during the current study are available from the corresponding author on reasonable request.

\section{Declarations}

Ethics approval and consent to participate

Not applicable.

\section{Consent for publication}

Not applicable.

\section{Competing interests}

The author declares no competing interests associated with this manuscript.

Received: 25 October 2021 Accepted: 8 February 2022

Published online: 18 February 2022

\section{References}

Baran I, Stewart MP, Kampes BM et al (2003) A modification to the Goldstein radar interferogram filter. IEEE Trans Geosci Remote Sens 41:2114-2118. https://doi.org/10.1109/TGRS.2003.817212

Biggs J, Wright T, Lu Z, Parsons B (2007) Multi-interferogram method for measuring interseismic deformation: Denali Fault, Alaska. Geophys J Int 170:1165-1179. https://doi.org/10.1111/j.1365-246X.2007.03415.x

Chen CW, Zebker HA (2000) Network approaches to two-dimensional phase unwrapping: intractability and two new algorithms. J Opt Soc Am A Opt Image Sci vis 17:401-414. https://doi.org/10.1364/JOSAA.18.001192

Chen CW, Zebker HA (2001) Two-dimensional phase unwrapping with use of statistical models for cost functions in nonlinear optimization. J Opt Soc Am A 18:338. https://doi.org/10.1364/JOSAA.18.000338

Chen CW, Zebker HA (2002) Phase unwrapping for large SAR interferograms: Statistical segmentation and generalized network models. IEEE Trans Geosci Remote Sens 40:1709-1719. https://doi.org/10.1109/TGRS.2002. 802453

Fujiwara S, Yarai H, Kobayashi T et al (2016) Small-displacement linear surface ruptures of the 2016 Kumamoto earthquake sequence detected by ALOS-2 SAR interferometry. Earth Planets Space 68:160. https://doi.org/ 10.1186/s40623-016-0534-x

Fujiwara S, Nakano T, Morishita Y (2020) Detection of triggered shallow slips caused by large earthquakes using L-band SAR interferometry. Earth Planets Space 72:119. https://doi.org/10.1186/s40623-020-01239-6

Gomba G, Parizzi A, De Zan F et al (2016) Toward operational compensation of ionospheric effects in SAR interferograms: the split-spectrum method. IEEE Trans Geosci Remote Sens 54:1446-1461. https://doi.org/10.1109/ TGRS.2015.2481079

Hanssen RF (2001) Radar interferometry. Springer Netherlands, Dordrecht

Jet Propulsion Laboratory (2020) NASA-ISRO SAR mission (NISAR). https://nisar. jpl.nasa.gov/. Accessed 18 Aug 2021

Kobayashi T (2016) Effect of atmospheric-related noise reduction using numerical weather model for InSAR analysis. J Geod Soc Japan 62:79-88. https://doi.org/10.11366/sokuchi.62.79 (in Japanese with English abstract)

Lazecký M, Spaans K, González PJ et al (2020) LiCSAR: an automatic InSAR tool for measuring and monitoring tectonic and volcanic activity. Remote Sens 12:2430. https://doi.org/10.3390/rs12152430

Massonnet D, Rossi M, Carmona C et al (1993) The displacement field of the Landers earthquake mapped by radar interferometry. Nature 364:138142. https://doi.org/10.1038/364138a0

Morishita Y (2019) A systematic study of synthetic aperture radar interferograms produced from ALOS-2 data for large global earthquakes from 2014 to 2016. IEEE J Sel Top Appl Earth Obs Remote Sens 12:2397-2408. https://doi.org/10.1109/jstars.2019.2921664

Morishita Y, Kobayashi T, Yarai H (2016) Three-dimensional deformation mapping of a dike intrusion event in Sakurajima in 2015 by exploiting the right- and left-looking ALOS-2 InSAR. Geophys Res Lett 43:4197-4204. https://doi.org/10.1002/2016GL068293 
Morishita Y, Kobayashi T, Fujiwara S, Yarai H (2018) Complex crustal deformation of the 2016 Kaikoura, New Zealand, earthquake revealed by ALOS-2. Bull Seismol Soc Am 108:1746-1756. https://doi.org/10.1785/0120170143

Morishita Y, Lazecky M, Wright TJ et al (2020) LiCSBAS: an open-source InSAR time series analysis package integrated with the LiCSAR automated sentinel-1 InSAR processor. Remote Sens 12:424. https://doi.org/10.3390/ rs 12030424

Motohka T, Kankaku Y, Miura S, Suzuki S (2019) ALOS-4 L-band SAR mission and observation. In: international geoscience and remote sensing symposium (IGARSS). Institute of Electrical and Electronics Engineers Inc., pp 5271-5273

Motohka T, Kankaku Y, Miura S, Suzuki S (2020) ALOS-4 L-band SAR observation concept and development status. In: international geoscience and remote sensing symposium (IGARSS). Institute of Electrical and Electronics Engineers Inc., pp 3792-3794

Nakata T, Imaizumi T (2002) Digital active fault map of Japan. Univ Tokyo Press, Tokyo, p 60

Oliver-Cabrera T, Jones CE, Yunjun Z, Simard M (2021) InSAR phase unwrapping error correction for rapid repeat measurements of water level change in wetlands. IEEE Trans Geosci Remote Sens. https://doi.org/10. 1109/TGRS.2021.3108751

Sandwell DT, Price EJ (1998) Phase gradient approach to stacking interferograms. J Geophys Res Solid Earth 103:30183-30204. https://doi.org/10. 1029/1998JB900008

Sica F, Calvanese F, Scarpa G, Rizzoli P (2020) A CNN-based coherence-driven approach for InSAR phase unwrapping. IEEE Geosci Remote Sens Lett. https://doi.org/10.1109/LGRS.2020.3029565

Tobita M (2003) Development of SAR interferometry analysis and its application to crustal deformation study. J Geod Soc Japan 49:1-23. https://doi. org/10.11366/sokuchi1954.49.1 (in Japanese with English abstract)

Touzi R, Lopes A, Bruniquel J, Vachon PW (1999) Coherence estimation for SAR imagery. IEEE Trans Geosci Remote Sens 37:135-149. https://doi.org/10. $1109 / 36.739146$

Wegmüller U, Werner C, Frey O et al (2018) Reformulating the split-spectrum method to facilitate the estimation and compensation of the ionospheric phase in SAR interferograms. Procedia Comput Sci 138:318-325. https:// doi.org/10.1016/j.procs.2018.10.045

Werner C, Wegmüller U, Strozzi T, Wiesmann A (2002) Processing strategies for phase unwrapping for INSAR applications. In: proceedings of the European conference on synthetic aperture radar EUSAR

Wu Z, Wang T, Wang Y et al (2021) Deep-learning based phase discontinuity prediction for two-dimensional phase unwrapping of SAR interferograms. IEEE Trans Geosci Remote Sens. https://doi.org/10.1109/TGRS. 2021.3121906

Xu X, Sandwell DT, Ward LA et al (2020) Surface deformation associated with fractures near the 2019 Ridgecrest earthquake sequence. Science 370:605-608. https://doi.org/10.1126/science.abd1690

Yu H, Lan Y, Yuan Z et al (2019) Phase unwrapping in InSAR: a review. IEEE Geosci Remote Sens Mag 7:40-58. https://doi.org/10.1109/MGRS.2018. 2873644

Yunjun Z, Fattahi H, Amelung F (2019) Small baseline InSAR time series analysis: unwrapping error correction and noise reduction. Comput Geosci 133:104331. https://doi.org/10.1016/J.CAGEO.2019.104331

Zebker HA, Lu Y (1998) Phase unwrapping algorithms for radar interferometry: residue-cut, least-squares, and synthesis algorithms. J Opt Soc Am A 15:586. https://doi.org/10.1364/JOSAA.15.000586

Zhou L, Yu H, Lan Y (2020) Deep convolutional neural network-based robust phase gradient estimation for two-dimensional phase unwrapping using SAR interferograms. IEEE Trans Geosci Remote Sens 58:4653-4665. https://doi.org/10.1109/TGRS.2020.2965918

Zhou L, Yu H, Lan Y, Xing M (2021) Deep learning-based branch-cut method for InSAR two-dimensional phase unwrapping. IEEE Trans Geosci Remote Sens. https://doi.org/10.1109/TGRS.2021.3099997

\section{Publisher's Note}

Springer Nature remains neutral with regard to jurisdictional claims in published maps and institutional affiliations.

\section{Submit your manuscript to a SpringerOpen ${ }^{\circ}$ journal and benefit from:}

- Convenient online submission

- Rigorous peer review

- Open access: articles freely available online

- High visibility within the field

- Retaining the copyright to your article

Submit your next manuscript at $\boldsymbol{\nabla}$ springeropen.com 